\title{
Synaptic Interactome Mining Reveals p140Cap as a New Hub for PSD Proteins Involved in Psychiatric and Neurological Disorders
}

\section{OPEN ACCESS}

Edited by:

Carlo Sala

Institute of Neuroscience (CNR), Italy

Reviewed by:

Christian Gonzalez-Billault,

Universidad de Chile, Chile

Pierre Billuart

Institut National de la Santé et de la

Recherche Médicale (INSERM)

France

*Correspondence:

Emilia Turco

emilia.turco@unito.it

Paola Defilipp

paola.defilippi@unito.it

${ }^{\dagger}$ These authors have contributed equally to this work.

Received: 29 March 2017 Accepted: 15 June 2017

Published: 30 June 2017

Citation:

Alfieri A, Sorokina O, Adrait A, Angelini C, Russo I, Morellato A, Matteoli M, Menna E, Boeri Erba E,

McLean C, Armstrong JD, Ala U,

Buxbaum JD, Brusco A, Couté Y, De

Rubeis S, Turco E and Defilippi P (2017) Synaptic Interactome Mining Reveals p140Cap as a New Hub for PSD Proteins Involved in Psychiatric and Neurological Disorders.

Front. Mol. Neurosci. 10:212. doi: 10.3389/fnmol.2017.00212

\begin{abstract}
Annalisa Alfieri ${ }^{1 \dagger}$, Oksana Sorokina ${ }^{2 \dagger}$, Annie Adrait ${ }^{3,4,5}$, Costanza Angelini ${ }^{1}$, Isabella Russo ${ }^{1}$, Alessandro Morellato ${ }^{1}$, Michela Matteoli ${ }^{6,7}$, Elisabetta Menna ${ }^{6,7}$, Elisabetta Boeri Erba ${ }^{8,9,10}$, Colin McLean ${ }^{2}$, J. Douglas Armstrong ${ }^{2}$, Ugo Ala ${ }^{1,11}$, Joseph D. Buxbaum 12, 13, 14, 15, 16, 17, Alfredo Brusco ${ }^{18,19}$, Yohann Couté ${ }^{3,4,5}$, Silvia De Rubeis ${ }^{12,13}$, Emilia Turco ${ }^{1 *}$ and Paola Defilippi ${ }^{1 *}$
\end{abstract}

${ }^{1}$ Department of Molecular Biotechnology and Health Sciences, Molecular Biotechnology Center, Università di Torino, Torino, Italy, ${ }^{2}$ The Institute for Adaptive and Neural Computation, School of Informatics, University of Edinburgh, Edinburgh, United Kingdom, ${ }^{3}$ Université Grenoble Alpes, iRTSV-BGE, Grenoble, France, ${ }^{4}$ CEA, iRTSV-BGE, Grenoble, France, ${ }^{5}$ Institut National de la Santé et de la Recherche Médicale, BGE, Grenoble, France, ${ }^{6}$ Institute of Neuroscience, Consiglio Nazionale delle Ricerche (CNR), Milan, Italy, ${ }^{7}$ Humanitas Clinical and Research Center, IRCCS, Rozzano, Italy, ${ }^{8}$ Institut de Biologie Structurale, Université Grenoble Alpes, Grenoble, France, ${ }^{9} \mathrm{CEA}, \mathrm{DSV}$, IBS, Grenoble, France, ${ }^{10}$ Centre National de la Recherche Scientifique, IBS, Grenoble, France, ${ }^{11}$ GenoBiToUS-Genomics and Bioinformatics, Università di Torino, Turin, Italy, ${ }^{12}$ Seaver Autism Center for Research and Treatment, Department of Psychiatry, Icahn School of Medicine at Mount Sinai, New York, NY, United States, ${ }^{13}$ Department of Psychiatry, Icahn School of Medicine at Mount Sinai, New York, NY, United States, ${ }^{14}$ Department of Neuroscience, Icahn School of Medicine at Mount Sinai, New York, NY, United States, ${ }^{15}$ Friedman Brain Institute, Icahn School of Medicine at Mount Sinai, New York, NY, United States, ${ }^{16}$ Department of Genetics and Genomic Sciences, Icahn School of Medicine at Mount Sinai, New York, NY, United States, ${ }^{17}$ Mindich Child Health and Development Institute, Icahn School of Medicine at Mount Sinai, New York, NY, United States, ${ }^{18}$ Department of Medical Sciences, Università di Torino, Turin, Italy, ${ }^{19}$ Medical Genetics Unit, Azienda Ospedaliera Città della Salute e della Scienza di Torino, Turin, Italy

Altered synaptic function has been associated with neurological and psychiatric conditions including intellectual disability, schizophrenia and autism spectrum disorder (ASD). Amongst the recently discovered synaptic proteins is p140Cap, an adaptor that localizes at dendritic spines and regulates their maturation and physiology. We recently showed that p140Cap knockout mice have cognitive deficits, impaired long-term potentiation (LTP) and long-term depression (LTD), and immature, filopodia-like dendritic spines. Only a few p140Cap interacting proteins have been identified in the brain and the molecular complexes and pathways underlying p140Cap synaptic function are largely unknown. Here, we isolated and characterized the p140Cap synaptic interactome by co-immunoprecipitation from crude mouse synaptosomes, followed by mass spectrometry-based proteomics. We identified 351 p140Cap interactors and found that they cluster to sub complexes mostly located in the postsynaptic density (PSD). p140Cap interactors converge on key synaptic processes, including transmission across chemical synapses, actin cytoskeleton remodeling and cell-cell junction organization. Gene co-expression data further support convergent functions: the p140Cap interactors are tightly co-expressed with each other and with p140Cap. Importantly, the p140Cap interactome and its co-expression network show strong enrichment in genes associated with schizophrenia, autism, bipolar disorder, intellectual disability and epilepsy, supporting 
synaptic dysfunction as a shared biological feature in brain diseases. Overall, our data provide novel insights into the molecular organization of the synapse and indicate that p140Cap acts as a hub for postsynaptic complexes relevant to psychiatric and neurological disorders.

Keywords: p140Cap, postsynaptic density, synaptic transmission, synaptic plasticity, schizophrenia, autism, intellectual disability, epilepsy

\section{INTRODUCTION}

Mutations in genes encoding synaptic proteins have been associated with several brain disorders, including schizophrenia, autism spectrum disorder (ASD) and developmental delay/intellectual disability (DD/ID) (De Rubeis et al., 2014; Fromer et al., 2014; Deciphering Developmental Disorders, 2015). The term "synaptopathies" has in fact been proposed to cover a broad range of clinical manifestations having synaptic dysfunction as common etiology (Grant, 2012). The synaptic genes implicated in brain diseases span several functional classes, including adhesion molecules (e.g., NRXN1; Kim et al., 2008), neurotransmitter receptors (e.g., GRIN2B ; Endele et al., 2010), voltage-gated ion channels (e.g., SCN2A; Rauch et al., 2012), scaffolding proteins of the postsynaptic density (PSD) (e.g., SHANK3; Betancur and Buxbaum, 2013) and signaling proteins (e.g., SYNGAP1; Hamdan et al., 2009).

Enormous progress has been made in the characterization of the synaptic proteome (Bayes et al., 2014), and the molecular and functional dissection of specific subsynaptic complexes is likely to reveal novel genes relevant to brain pathophysiology. Amongst the recently discovered synaptic proteins is p140Cap/SNIP (Chin et al., 2000; Di Stefano et al., 2004), a scaffolding protein localized in dendritic spines (Jaworski et al., 2009) and encoded by the SRCIN1 gene. Previous work from our laboratory and others indicates that p140Cap is key in regulating synaptogenesis, synaptic transmission and synaptic plasticity (Jaworski et al., 2009; Tomasoni et al., 2013; Repetto et al., 2014). Acute down-regulation of p140Cap in primary hippocampal neurons reduces the number of mushroom spines and proportionally increases the number of dendritic filopodia (Jaworski et al., 2009; Tomasoni et al., 2013), a defect in synaptic maturation that can also be observed in p140Cap knockout (KO) mice (Repetto et al., 2014). Notably, dendritic spine dysgenesis is a consistent neuroanatomical finding in several psychiatric disorders, including ID, ASD and schizophrenia (Penzes et al., 2011). Further, p140Cap KO mice display defective long-term potentiation (LTP) and reduced long-term depression (LTD), two forms of synaptic plasticity necessary for learning and memory. Consistently, p140Cap KO mice show impairments in object recognition, suggestive of defects in memory consolidation and retrieval cognitive defects (Repetto et al., 2014).

The molecular complexes and pathways underlying p140Cap function are largely unknown. p140Cap was originally identified as an interactor of SNAP-25 in a two-hybrid screen (Chin et al., 2000) and subsequent studies have shown that this interaction takes place in the PSD, involving also PSD95, and is required for spine morphogenesis (Tomasoni et al., 2013;
Fossati et al., 2015). p140Cap had been also shown to interact with other components of the pre-synaptic compartment, such as vinexin and synaptophysin (Ito et al., 2008). Other interactions necessary for p140Cap-mediated control of spine formation and/or maturation are those with the EB3 (Jaworski et al., 2009), Endophilin A1 (Yang et al., 2015), and Src kinase (Di Stefano et al., 2007; Repetto et al., 2013, 2014). EB3 binds the plusend of growing microtubules that can enter dendritic spines and influence their morphology (Jaworski et al., 2009). Endophilin A1 is localized both presynaptically, where it regulates synaptic vesicle endocytosis, and postsynaptically, where it controls spine morphogenesis (Yang et al., 2015). The correct functioning of both EB3 and Endophilin A1 requires p140Cap and its downstream effector cortactin, an F-actin-binding protein, that regulates the actin cytoskeleton organization (Uruno et al., 2001). The p140Cap-dependent regulation of cortactin activity might require a direct interaction as well as the suppression of the Src kinase pathway. In fact, cortactin is inhibited by Src phosphorylation (Martinez-Quiles et al., 2004), and p140Cap directly binds Src (Di Stefano et al., 2007) and suppresses its activation through binding to the C-terminal Src kinase (Csk) (Di Stefano et al., 2007; Repetto et al., 2013). Consistently, synapses isolated from p140Cap KO mice have increased phosphorylation on Src kinase Tyrosine 416 (Repetto et al., 2014) and treatment with a specific Src inhibitor ameliorates the spine defects observed in p140Cap KO neurons (Repetto et al., 2014). Beyond its role in spine morphology, p140Cap-mediated suppression of Src has been recently implicated in the homeostatic brake that restrains cocaine reward in the nucleus accumbens (DamezWerno et al., 2016).

Given the role of p140Cap in synaptogenesis and the repercussions on cognition in its absence, we sought to capture the p140Cap molecular complexes at synapses and investigate their relevance for brain disorders. By using biochemical, proteomic, gene co-expression, and genetic data, we provide a comprehensive analysis of the p140Cap synaptic interactome. Our results reveal that $\mathrm{p} 140 \mathrm{Cap}$ acts as a hub for synaptic proteins implicated in psychiatric and neurological disorders.

\section{MATERIALS AND METHODS}

\section{Animals}

Mixed 129Sv $\times$ C57BL/6J p140Cap heterozygous mice were generated as described in (Repetto et al., 2014). All experiments were approved and performed in accordance with the Italian law (authorization D.M. $\mathrm{n}^{\circ}$ 279/95B 27/11/1995) and dispositions of "D.L. $\mathrm{n}^{\circ} 116,27 / 1 / 1992$ in relation to animal use and protection in scientific research." Male, 3-month old wild-type (WT) and 
p140Cap knockout (KO) littermates were used for synaptosomes preparations. Animals were sacrificed by cervical dislocation.

\section{Synaptosomes Preparation}

Synaptosomes were prepared from the telencephalon. The tissue was homogenized with a Dounce glass homogenizer and glass pestle in $8 \mathrm{ml}$ ice-cold synaptosome buffer $(4 \mathrm{mM}$ Hepes $\mathrm{pH}=7.3,320 \mathrm{mM}$ sucrose, $1 \mathrm{mM}$ EGTA, Roche protease inhibitors 25X, $1 \mathrm{mM}$ Sodium Orthovanadate, $1 \mathrm{mM}$ DTT, phenylmethylsulphonyl fluoride, $1 \mathrm{mM}$ sodium fluoride). The homogenate was centrifuged at $1,000 \mathrm{~g}$ for $10 \mathrm{~min}$ at $4^{\circ} \mathrm{C}$. After discarding the nuclear pellet, the supernatant was centrifuged at $12,500 \mathrm{~g}$ for $20 \mathrm{~min}$ at $4^{\circ} \mathrm{C}$. The pellet containing the synaptosomal fraction was resuspended in the synaptosome buffer and further centrifuged at $12,500 \mathrm{~g}$ for $20 \mathrm{~min}$ at $4^{\circ} \mathrm{C}$. The final pellet (crude synaptosome fraction) was resuspended in $2 \mathrm{ml}$ of ice-cold lysis buffer $(150 \mathrm{mM} \mathrm{NaCl}, 50 \mathrm{mM}$ Tris $\mathrm{pH}$ $=7,5 \%$ Glycerol, $1 \% \mathrm{NP}-40,1 \mathrm{mM} \mathrm{MgCl}$, Roche protease inhibitors $25 \mathrm{X}, 1 \mathrm{mM}$ Sodium Orthovanadate, $1 \mathrm{mM}$ DTT, phenylmethylsulphonyl fluoride, $1 \mathrm{mM}$ sodium fluoride) and immediately processed for immunoprecipitation (Figure S1).

\section{Western Blot}

Western blots were performed with Mini-PROTEAN ${ }^{\circledR} \mathrm{TGX}^{\mathrm{TM}}$ Precast Gels from Bio-Rad (California 94547 USA).gradient 4$15 \%$ Gels were transferred on Nitrocellulose blotting membrane (GE Healthcare Life Sciences) using Towbin buffer $(25 \mathrm{mM}$ Tris, $192 \mathrm{mM}$ Glycine, 20\% Methanol). Membranes were blocked with Tris-buffered saline TBS $(50 \mathrm{mM}$ Tris $\mathrm{p}<\mathrm{h} 7-150 \mathrm{mM}$ $\mathrm{NaCl}$ ) with $5 \%$ Milk for $1 \mathrm{~h}$ at room temperature, incubated with primary and secondary antibodies as indicated below, and then developed with Bio-Rad's Clarity ECL on ChemiDoc Touch Imaging System (Biorad). For western blot of crude synaptosomal proteins, 30 ug of proteins was used.

\section{Antibodies}

Specific mouse monoclonal antibody (Mab) against p140Cap (clone 2A8) was produced at the MBC, University of Torino, as previously described (Di Stefano et al., 2007; Repetto et al., 2013). The antibodies used are as follows: Dlg4 (Mab, Abcam), Citron-N (rabbit polyclonal, Abcam), Grin2A (rMab from Millipore; rabbit polyclonal from Thermo Scientific), Grin2b (mouse monoclonal antibody, Neuromab), Grin1 rabbit polyclonal (Thermo Scientific), Shank2 (rabbit polyclonal, Synaptic System), Shank3 (rabbit polyclonal, Synaptic System), Snap25 (Mab, Synaptic System), Actin I-19 (rabbit polyclonal, Santa Cruz Biotechnology), Trio (rabbit polyclonal, Santa Cruz Biotechnology), rabbit polyclonal Camk2 (Cell Signaling), Homer-1 (rabbit polyclonal, Thermo Scientific), Cadherin-11 (Mab, Thermo Scientific), Syncam (rabbit polyclonal, Thermo Scientific), Ttc3 (rabbit polyclonal, as described in Berto et al., 2007), and Gfap (Mab, Dako-Agilent Technologies), Bassoon (rabbit polyclonal, Synaptic System). Mouse and rabbit IgGs were purchased from Santa Cruz Biotechnology. Secondary antibodies anti-mouse and anti-rabbit were purchased from Sigma Aldrich.

\section{p140Cap Immunoprecipitation}

$1.25 \mathrm{mg}$ of Dynabeads protein G $\left(30 \mathrm{mg}\right.$ Dynabeads ${ }^{\circledR} / \mathrm{mL}$ Invitrogen, Carlsbad, CA, USA) were initially washed using a Sodium Acetate buffer ( $100 \mathrm{mM}$ Sodium acetate $\mathrm{pH}=5,0.1 \%$ NP-40) and incubated with $6 \mu \mathrm{g}$ of p140Cap antibody diluted in the same buffer for $1 \mathrm{~h}$ at room temperature under gentle rotation. Beads were then washed twice withSodium acetate buffer and with Sodium Borate buffer $(0.2 \mathrm{M}$ Sodium borate $\mathrm{pH}=9,0.1 \%$ NP-40) Crosslinking was performed with $25 \mathrm{mM}$ Dymethil Pimelimidate in $1 \mathrm{ml}$ of Sodium Borate buffer for 45 min at room temperature on a wheel. Beads were washed again with Sodium Borate buffer and then with $0.2 \mathrm{M}$ Ethanolamine $\mathrm{pH}=8,0.1 \% \mathrm{NP}-40$, incubated for $1 \mathrm{~h}$ at $\mathrm{RT}$ on a wheel to block the N-reactive groups and washed twice in PBS $0.1 \% \mathrm{NP}-40$. To remove the non-cross-linked antibody, beads were suspended in $100 \mathrm{mM}$ Glycine $\mathrm{pH}=2.5$ and rapidly washed in $50 \mathrm{mM}$ Tris $\mathrm{pH}=7.40 .1 \%$ NP-40. p140Cap-coupled Dynabeads were then washed twice with PBS 1X 0.05\% Tween and then incubated with $6 \mathrm{mg}$ of crude synaptosomal extracted for $2 \mathrm{~h}$ at $4^{\circ} \mathrm{C}$. Beads were washed five times with cold lysis buffer, then resuspended in $60 \mu \mathrm{l}$ of $2 \%$ SDS-PAGE sample buffer in reducing conditions and incubated at $70^{\circ} \mathrm{C}$ for $10 \mathrm{~min}$. From this $1 \mathrm{mg}$ was tested for Coomassie staining, $1 \mathrm{mg}$ for Western blot for p140Cap to control the quality of the samples and $4 \mathrm{mg}$ was used for mass spectrometry (Figure S2).

\section{Primary Hippocampal Cultures}

Primary cultures were established from the hippocampus of 17.5-18.5 embryos derived from breeding of p140Cap \pm mice. The dissociated cells were plated on $20 \mathrm{~mm}$ coverslip coated with poly-lysine at the density of 80,000 cells/coverslip and cultured in Neurobasal medium (Invitrogen) added with B27 (Invitrogen), supplemented with antibiotics, $2 \mathrm{mM}$ glutamine and glutamate for $17-18$ days at $37^{\circ} \mathrm{C}$. Neurons were then fixed in paraformaldehyde $4 \%$ and sucrose $4 \%$ (Sigma Aldrich) for $8 \mathrm{~min}$ at room temperature.

\section{Immunofluorescence and Microscopy}

Immunofluorescence staining was performed using antibodies against PSD95 (1:500 mouse monoclonal Abcam) and p140Cap homemade monoclonal antibody conjugated with Alexa Fluor 647 Antibody labeling kit (Thermo Fisher) diluted 1:500. Coverslips were first incubated with anti-PSD95 and then with Alexa fluor 488 goat anti mouse (Invitrogen); after several washes of the secondary antibody, conjugated anti-p140Cap Mab was added for $1 \mathrm{~h}$ at room temperature and then washed away. Images were acquired using a Leica SPE confocal microscope.

\section{Mass Spectrometry}

(1) Preparation and in-gel digestion of proteins: proteins from co-IP eluates were stacked in the top of a $4-12 \%$ NuPAGE gel (Invitrogen) and stained with R-250 Coomassie blue. Gel bands were manually excised and cut in pieces before being washed six times with $25 \mathrm{mM} \mathrm{NH}_{4} \mathrm{HCO}_{3}$ for $15 \mathrm{~min}$, followed by six washes in $25 \mathrm{mM} \mathrm{NH}_{4} \mathrm{HCO}_{3}$ containing $50 \%$ $(\mathrm{v} / \mathrm{v})$ acetonitrile. Gel pieces were then dehydrated with $100 \%$ acetonitrile and incubated with $10 \mathrm{mM}$ DTT in $25 \mathrm{mM}$ 
$\mathrm{NH}_{4} \mathrm{HCO}_{3}$ for $45 \mathrm{~min}$ at $53^{\circ} \mathrm{C}$ and with $55 \mathrm{mM}$ iodoacetamide in $25 \mathrm{mM} \mathrm{NH}_{4} \mathrm{HCO}_{3}$ for $35 \mathrm{~min}$ in the dark. Alkylation was stopped by adding $10 \mathrm{mM}$ DTT in $25 \mathrm{mM} \mathrm{NH}_{4} \mathrm{HCO}_{3}$ (incubation for $10 \mathrm{~min}$ ). Gel pieces were then washed again by incubation in $25 \mathrm{mM} \mathrm{NH}_{4} \mathrm{HCO}_{3}$ followed by dehydration with $100 \%$ acetonitrile. Modified trypsin (Promega, sequencing grade) in $25 \mathrm{mM} \mathrm{NH} \mathrm{NCO}_{3}$ was added to the dehydrated gel pieces before overnight incubation at $37^{\circ} \mathrm{C}$. Peptides were extracted from gel pieces in three sequential extraction steps (each $15 \mathrm{~min}$ ) using $30 \mu \mathrm{l}$ of $50 \%$ acetonitrile, $30 \mu \mathrm{l}$ of $5 \%$ formic acid, and finally $30 \mu \mathrm{l}$ of $100 \%$ acetonitrile. The pooled supernatants were dried under vacuum. (2) Nano-LCMS/MS analyses: the dried extracted peptides were resuspended in $5 \%$ acetonitrile and $0.1 \%$ trifluoroacetic acid and analyzed by online nanoLC-MS/MS (UltiMate 3000 RSLCnano and QExactive Plus, Thermo Scientific) with 2 replicates per sample. Peptides were sampled on a $300 \mu \mathrm{m}$ x $5 \mathrm{~mm}$ PepMap C18 precolumn and separated on a $75 \mu \mathrm{m} \times 250 \mathrm{~mm} \mathrm{C18}$ column (PepMap, Dionex). The nanoLC method consisted of a 120min gradient at a flow rate of $300 \mathrm{nl} / \mathrm{min}$, ranging from 5 to $37 \%$ acetronitrile in $0.1 \%$ formic acid for $114 \mathrm{~min}$, before reaching $72 \%$ acetronitrile in $0.1 \%$ formic acid for the last $6 \mathrm{~min}$. Spray voltage was set at $1.6 \mathrm{kV}$; heated capillary was adjusted to $270^{\circ} \mathrm{C}$. Survey full-scan MS spectra $(\mathrm{m} / \mathrm{z}=400-1,600)$ were acquired with a resolution of 70,000 after accumulation of $10^{6}$ ions (maximum filling time $200 \mathrm{~ms}$ ). The 10 most intense ions were fragmented by higher-energy collisional dissociation after accumulation of $10^{5}$ ions (maximum filling time 50 $\mathrm{ms}$ ). MS and MS/MS data were acquired using the software Xcalibur (Thermo Scientific). (3) Data analyses: RAW files were processed using MaxQuant, version 1.5.1.2 (Cox and Mann, 2008). Spectra were searched against the Uniprot database (Mus musculus taxonomy, March 2015 version) and the frequently observed contaminants database embedded in MaxQuant. The $\mathrm{I}=\mathrm{L}$ option was activated. Trypsin was chosen as the enzyme and 2 missed cleavages were allowed. Peptide modifications allowed during the search were: carbamidomethylation (C, fixed), acetyl (Protein N-ter, variable) and oxidation ( $\mathrm{M}$, variable). Minimum number of unique peptides was set to 1 . The matching between runs option was activated. The mass spectrometry proteomics data have been deposited to the ProteomeXchange Consortium via the PRIDEpartner repository (Vizcaino et al., 2016) with the dataset identifier PXD004215. (4) Statistical analyses: The following steps were mainly performed using the Perseus toolbox (version 1.5.1.6) available in the MaxQuant environment. Proteins identified in the reverse and contaminant databases, identified with less than 2 razor + unique peptides, or exhibiting less than 6 iBAQ values in one condition (3 biological replicates with 2 analytical replicates each for control and p140Cap co-IPs) were discarded from the list. iBAQ values of the 1952 remaining proteins. After $\log 2$ transformation, iBAQ values were normalized by condition-wise centering, missing data imputation was realized (replacing missing values by a constant weak value calculated independently for each injected sample as the 2.5-percentile value of the column) and statistical testing of differential abundances between control and p140Cap conditions were conducted using welch $t$-testing. To consider a protein as a potential binding partner of p140Cap, it must has passed our significance criteria: FDR threshold of $1 \%$ on $p$ values using the Benjamini-Hochberg method and a minimum 4-times enrichment in p140Cap WT samples compared to the $\mathrm{KO}$ controls.

\section{Bioinformatic Analyses of MS Data}

Throughout the study, over-representation of annotation terms (disease, function etc.) was estimated by use of the hypergeometric distribution to test whether the number of selected proteins is larger than would be expected by chance;

$$
p=1-\sum_{i=0}^{k-1} \frac{\left(\frac{M}{i}\right)\left(\frac{N-M}{n-i}\right)}{\left(\frac{N}{n}\right)}
$$

where $N$ is a total number of proteins in the background distribution, $M$ is the number of genes within distribution that are annotated to the node of interest, $n$ is the size of the list of genes of interest and $k$ is the number of genes within the list, which are annotated to the node. Obtained $p$-values were adjusted for multiple testing by Bonferroni correction at 0.05 or 0.01 significance levels as indicated.

For literature comparison, a list of 6,688 proteins was selected as a synaptic universe based on combined results from 35 published synapse proteome studies (in preparation; Supplementary Table S2). Protein lists from those studies were curated, mapped to stable IDs (Entrez, Uniprot, MGI) for human and mouse and combined into single list containing only unique protein/gene name, IDs and publication source (PMID). Summary data for the 35 publications with associated metadata (PMID, year, method, species and number of proteins found) are presented in Supplementary Table S2).

Enrichment analysis of annotation in the interactome was performed in $\mathrm{R}$, specifically using the Bioconductor package ClusterProfiler for Gene Ontology (GO) and KEGG enrichment analysis (Yu et al., 2012) and Bioconductor ReactomePA package for pathway over-representation analysis (http://bioconductor. org/packages/release/bioc/html/ReactomePA.html). For each enrichment type (GO, KEGG, Reactome), two background sets of proteins were used: (1) the default mouse genome list from Bioconductor and (2) our list of 6688 published synaptic proteins-to reveal the consistency in enriched terms. $p$-values, adjusted for multiple comparison p.adjust and $q$-values for false discovery rates (FDR) are provided in Supplementary Table S3.

For disease enrichment the annotation data were standardized using MetaMap (Aronson and Lang, 2010) and NCBO Annotator (Whetzel et al., 2011; Musen et al., 2012) to recognize terms found in the Human Disease Ontology (HDO) (Schriml et al., 2012) Recognized enriched disease ontology terms were then associated with gene identifiers and stored locally. Disease term enrichment', for the p140Cap dataset', could then be calculated using the Topology-based Elimination Fisher method (Alexa et al., 2006) found in the topGO package (http://topgo.bioinfmpi-inf.mpg.de/), together with the standardized OMIM and Ensembl variation gene-disease annotation data (14111 genedisease associations), mapped onto the full HDO tree. 
A PSD network was constructed from a list of 1,443 proteins obtained from a study of the PSD in the human brain (Bayes et al., 2011). Protein-protein interactions were obtained by mining publicly available databases: HIPPIE (Schaefer et al., 2012), BioGRID (Chatr-Aryamontri et al., 2015), IntAct (Kerrien et al., 2012), and performing an InterologWalk over different species using Bio::Homology::InterologWalk (Gallone et al., 2011). The connected PSD network consists of 1,312 proteins and 8,031 protein interactions (i.e., 131 proteins could not be connected into the network). This PSD network was clustered making use of the spectral properties of the network; the network being expressed in terms of its eigenvectors and eigenvalues, and partitioned recursively (using a fine-tuning step) into communities based on maximizing the Modularity clustering measure (Newman, 2006; Simpson et al., 2010). Where first we found the node which, when moved from one community to the other, gave the maximum change in Modularity. This node's community was then fixed and we repeat the process until all nodes had been moved. The whole process was repeated from this new state until the change in the Modularity, between the new and old state, was less than the predefined tolerance. The modularity of the full PSD network was found to be 0.36 .

Robustness of the full PSD network communities was assessed by running the algorithm 500 times, randomly selecting $80 \%$ of the network node set and related interactions each time. The package clusterCons (Simpson et al., 2010) was used to build a consensus matrix from which to test the robustness of the communities, and proteins found inside the communities. Community and protein robustness values range from 0 , indicating no confidence in existing through to 1 , indicating absolute confidence in the cluster existing. Community robustness values range from 0.1 to 0.7 , and from 0.01 to 0.9 for protein robustness. Clusters C7, C17, C22, and C23 showed evidence of being robust, with community robustness values $0.2,0.4,0.3$, and 0.3 respectively.

We also tested the significance of annotation enrichment in each cluster using the Hypergeometric distribution formula. $P \leq 10^{-2}$, were tested for their strength of significance by recording the percentage of $P$-values found from every community/annotation combination, lower than or equal to the observed $P$-value, when 1,000 random permutations of the annotation labels were made. $P$-values found with a strength of significance $<1 \%$ were considered statistically significant. $P$-values values were also tested against a more stringent Bonferroni correction at the $0.05\left(^{*}\right), 0.01\left(^{* *}\right)$, and $0.001\left(^{* * *}\right)$ significant levels, and highlighted throughout the enrichment tables.

\section{Gene Co-expression Analysis}

Gene co-expression was evaluated on 18 human-mouse conserved co-expression networks (CCNs) (Piro et al., 2011), where a link of co-expression reflects the human and mouse independent gene co-expression in the corresponding singlespecies networks. Statistical significance of p140Cap interactors co-expressed with p140Cap was assessed by hypergeometric distribution. Statistical significance of the co-expression between p140Cap interactors was assessed by evaluating the $p$-value of the $\mathrm{z}$-score corresponding to the number of links found in the single CCNs, based on 100 randomization of the same CCNs.

\section{RESULTS}

\section{Quantitative Proteomic Analysis of p140Cap Synaptic Interactome}

To identify the p140Cap protein complexes and the related functional pathways at synapses, we performed a quantitative proteomic analysis of p140Cap immunoprecipitates from mouse crude synaptosomes preparations, using p140Cap KO mice (Repetto et al., 2014) as negative control (Figure S1). The quality of the preparations was verified by testing the enrichment of synaptic proteins in the crude synaptosome fraction compared to total brain extracts. PSD-95, SNAP-25, and Bassoon, as well as p140Cap, were enriched in synaptosomes (Figure 1A).

Three distinct crude synaptosomes were prepared from 3 month-old WT and p140Cap KO male mice and synaptosomal extracts were immunoprecipitated using p140Cap monoclonal antibody. The specificity of the immunoprecipitates (IP) was confirmed by Coomassie staining and western blot (Figure S2). In the Coomassie-stained gel, we detected a discrete band of $\sim 150 \mathrm{kDa}$, corresponding to the expected molecular weight for p140Cap in SDS-PAGE in the IPs from WT samples but not from p140Cap KO synaptosomes (Figure S2A). Similarly, a p140Cap immunoreactive band was observed in the p140Cap IPs from WT but not from KO synaptosomes (Figure S2B). The Coomassie-stained gel reveals that several proteins seem to selectively co-immunoprecipitate with p140Cap from WT samples as compared with the KO ones. Overall, these data indicate that the p140Cap immunoprecipitation is highly specific, thus making these samples suitable for the identification of p140Cap interactors by mass spectrometry (MS).

To identify p140Cap-binding partners, we applied label-free quantitative MS-based proteomics to the p140Cap IPs from WT and KO synaptosomes. Proteins eluted from the IPs were ingel digested and the resulting peptides analyzed by nanoliquid chromatography coupled to tandem MS (two analytical replicates per sample). Identities and intensities of the recovered peptides and proteins in each sample were obtained using MaxQuant (Cox and Mann, 2008). After filtering and statistical analysis of iBAQ values (Schwanhausser et al., 2011), 352 (351 interactors plus p140Cap) proteins enriched in the WT samples were identified (Supplementary Table S1), as represented in the Volcano plot (Figure 1B).

To validate the proteomic findings, we selected eleven candidates whose alterations might underlie the dendritic spine defects, the impairments in LTP/LTD, and the learning and memory deficits we previously observed in the p140Cap KO mice (Repetto et al., 2014). We then tested the presence of the selected proteins on the p140Cap IPs. We tested and validated p140Cap interactions with Citron-N, already known to interact with p140Cap (Repetto et al., 2014); the NMDA receptor subunits Grin2a, Grin2b and Grin1, the scaffold proteins Dlg4/PSD95, Shank2, Shank3, Homer1, and Camk2a. Alterations in expression or localization of several of these interactors are known to 


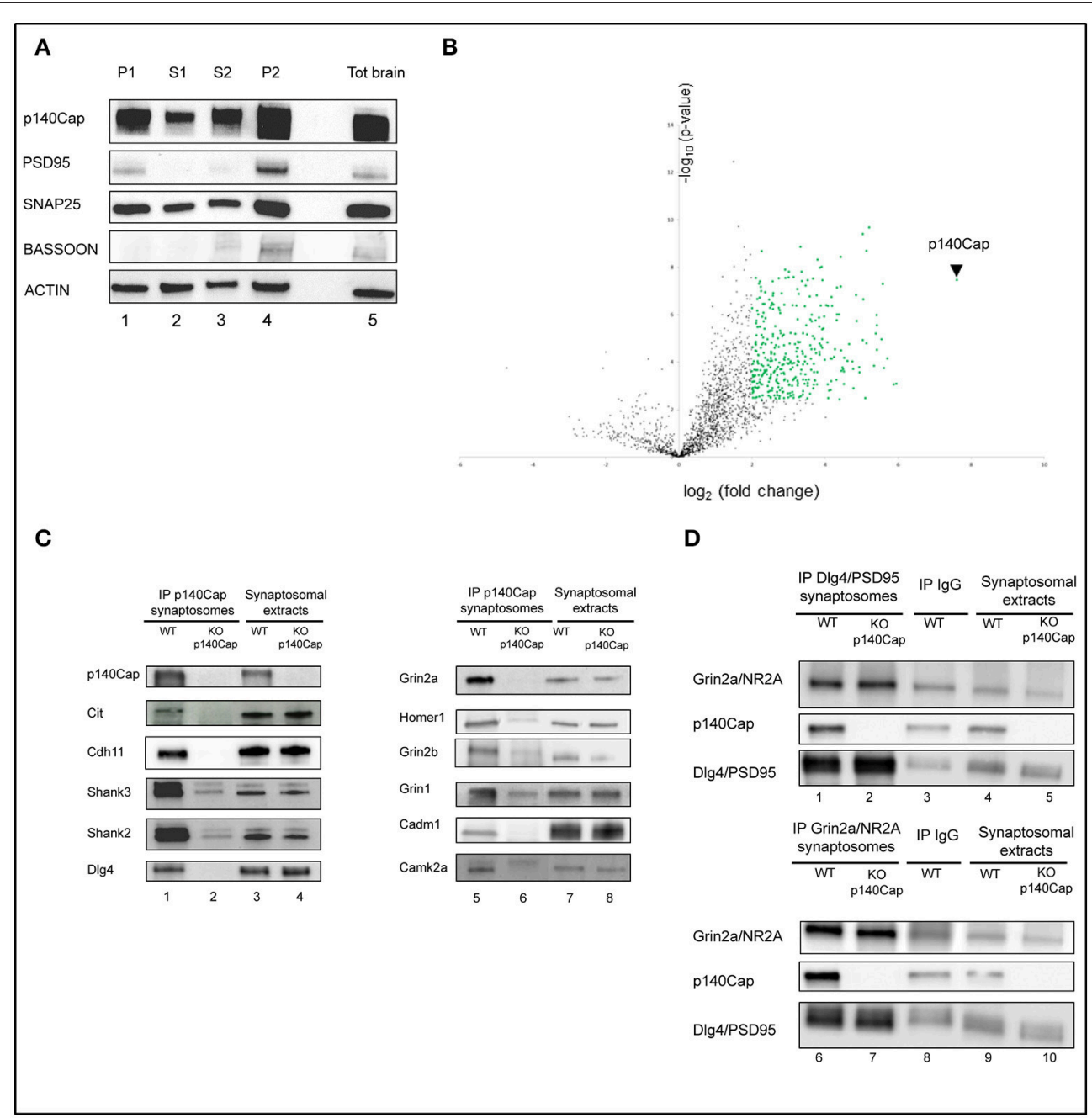

FIGURE 1 | Identification and validation of p140Cap interactors. Enrichment of synaptic markers in the synaptosomal preparation. (A) Validation of the synaptosomes. Western blot for p140Cap, PSD-95, Snap25, Bassoon and beta-actin fractions isolated during synaptosomal preparation. Lane 1, nuclear fraction (P1); lane 2, first cytosolic fraction (S1); lane 3, second cytosolic fraction (S2); lane 4, crude synaptosome (P2), lane 5, total brain extracts (see Figure S1 for details). (B) Statistically enriched proteins in the p140Cap IP. The Volcano plot represents the $\log _{10}$ ( $p$-value, y axis) plotted against the $\log _{2}$ (fold change, $x$ axis) for proteins quantified in p140Cap IPs from WT and p140Cap KO, used as negative control. 357 different proteins, including p140Cap (arrowhead) were found significantly enriched in WT samples (FDR $\leq 1 \%, \geq 4$-fold enrichment) are shown as green dots (C) Validation of synaptic p140Cap interacting proteins identified in the interactome. Lane 1 and 5, p140Cap IP in WT animals; lane 2 and 6, p140Cap IP in p140Cap KO animals; lane 3 and 7, input from WT synaptosomes; lane 4 and 8, input from KO synaptosomes. Co-immunoprecipitated proteins are shown on the left, along with their rank in MS. (D) Reverse validation for p140Cap interacting proteins Dlg4/PSD95 and Grin2a/NR2A. Lane 1, Dlg4/PSD95 IP in WT animals; lane 2, Dlg4/PSD95 IP in p140Cap KO animals; lane 4, input from WT synaptosomes; lane 5, input from KO synaptosomes; lane 6, Grin2a/NR2A IP in WT animals; lane 7, Grin2a/NR2A IP in p140Cap KO animals; lane 9, input from WT synaptosomes; lane 10, input from KO synaptosomes. Lane 3 and lane 8 are control IP with IgGs in WT animals.

affect LTP/LTD and cognitive functions (Grant, 2012; Luscher and Malenka, 2012; Robison, 2014; Sweatt, 2016). Further, we validated the interaction with the adhesion molecules Cadherin11 (Cdh11) (Manabe et al., 2000) and Cadm1/Syncam (Frei and Stoeckli, 2016; Figure 1C). We also verified that three proteins (Ttc3, Trio, and Gfap), placed very low in the interactome, were only non specifically immunoprecipitated with anti p140Cap Mab (Figure S3). Further, we performed a reverse validation: we immunoprecipitated PSD95 and Grin2a and verified the presence of p140Cap (Figure 1D). The validation of the proteomic data across a range of various enrichment levels above the fixed cut-off indicates that the p140Cap synaptic interactome we isolated contains bona fine p140Cap-containing macromolecular complexes.

\section{Synaptic Localisation of p140CAP Complexes with Comparative Study of Reported Synaptic Datasets}

To further map the p140Cap interactome, we searched published neuronal proteome datasets for p140Cap and its interactors. We found that p140Cap was reported in the majority of the 
published PSD datasets (Supplementary Table S2). In a few coIP studies, p140Cap was detected in complexes with PSD95 (Dosemeci et al., 2007), mGluR5 (Farr et al., 2004), Chmpb2 (Chassefeyre et al., 2018), and Snap25 (Fossati et al., 2015). Further, we searched for the 351 identified interactors of p140Cap across the published PSD proteomic datasets and found an exceptionally high enrichment (order of E-14 of significance in average) (Supplementary Table S2).

We also sought to verify whether p140Cap and associated proteins were found in presynaptic preparations as well, and we found that p140Cap was detected in the presynaptic compartment in several studies (Gronborg et al., 2010; Boyken et al., 2013; Weingarten et al., 2014). Specifically, it was detected in complexes with Rims1, Syn1-2-3, Git1, and Wasf1 in coIP experiments on presynaptic protein complexes (August B Smit, personal communication). However, it was not reported in other studies focusing on synaptic vesicles (SV) or SVrecycling proteins (Morciano et al., 2005, 2009; Gorini et al., 2010; Brinkmalm et al., 2014; Wilhelm et al., 2014). p140Capinteracting proteins, in turn, were found enriched in presynaptic datasets, although with a lower score than that found in postsynaptic studies (Supplementary Table S2). Therefore, our proteomic data, in agreement with previous studies, place p140Cap mainly, but not exclusively, in the PSD.

We then examined all the p140-interacting proteins to evaluate their distribution between pre- and postsynaptic complexes. The two lists showed a high degree of overlap, which was expected since the majority of synaptic proteins are found in both compartments. Figure 2A shows the distribution of the p140-interacting proteins between PSD (5023 proteins from 25 postsynaptic studies and presynaptic compartment (1215 proteins from 9 presynaptic studies). 334 of the 352 p140Cap interactors overlap with these datasets. Of these proteins, none were described as specifically presynaptic, whereas the majority was described as specifically postsynaptic (247) or found in both compartments (87). This further supports a predominantly postsynaptic localization of the p140Cap complexes.

The presence of p140Cap in the PSD has been previously shown in rat synaptic fractionation, where it is enriched in the PSD fraction together with PSD95 (Mclean Colin et al., 2016). To further validate the presence of p140Cap in the PSD, we performed a localization experiment on primary mouse hippocampal cultures. Staining of both p140Cap and PSD95 in Figure 2B shows a co-localization of these two proteins at synapses. All together, these results strongly indicate that the p140Cap-associated proteins share common cellular functions and fall within specific substructures of the PSD.

\section{Functional Enrichment Analyses of the p140CAP-Containing Protein Complexes}

To obtain a functional perspective of the p140Cap interactome, we tested its enrichment against KEGG, GO ontology and Reactome databases (Supplementary Table S3). We ran analysis against two reference (background) lists: (1) the default mouse genome list provided by Bioconductor and (2) a combined list of 6688 proteins from published synapse proteomics studies, to reveal more specific p140Cap associated terms compared to the whole synaptosome. Both reference lists demonstrated a very high level of consistency in top enriched terms. However, using the synaptic as background gives more conservative (i.e., lower) significance values for enriched terms. The full lists for enrichment results are presented in Supplementary Table 3.

For the enriched terms listed here, $p$-values were corrected for multiple testing as described in the methods. Based on Molecular Function (MF) ontology, the 351 p140Cap-interacting proteins were significantly enriched for the "actin binding" term $(P=2.79 \mathrm{E}-17)$, which is in line with the previously described functions of p140Cap (Repetto et al., 2014). Additionally, we found that "glutamate receptor binding" ( $P=3.46 \mathrm{E}-11)$, "PDZ domain binding" ( $P=1.22 \mathrm{E}-06)$ and "GTPase regulator activity" ( $P=2.86 \mathrm{E}-04)$ terms were also significantly increased (Supplementary Table S3). Among the top Cellular Compartment (CC) terms were "postsynaptic membrane" ( $P=3.08 \mathrm{E}-27)$, "actin cytoskeleton" $(P=2.87 \mathrm{E}-14)$, and "neurotransmitter receptor complex" $(P=8.53 \mathrm{E}-10)$. This is in agreement with Biological Process (BP) GO results, where the top enriched terms were "chemical synaptic transmission" $(P=1.81 \mathrm{E}-15)$, "actin cytoskeleton organization" $(P=4.37 \mathrm{E}-11)$, "regulation of synaptic plasticity" $(P=1.96 \mathrm{E}-09)$ and "regulation of protein complex assembly" ( $P=3.63 \mathrm{E}-06)$ (Supplementary Table S3). Analysis of enrichment against the Reactome pathway database revealed the overrepresentation for "Transmission across Chemical Synapses" ( $P=7.05 \mathrm{E}-15)$, "Unblocking of NMDA receptor, glutamate binding and activation" $(P=4.90 \mathrm{E}-$ $10)$, "Cell-cell junction organization" $(P=1.44 \mathrm{E}-08)$, "Ras activation upon Ca influx through NMDA receptor" $(P=2.49 \mathrm{E}-$ 08), "L1CAM interactions" ( $P=1.00 \mathrm{E}-07)$ (Supplementary Table S3).

To classify proteins into functionally related modules, we checked for the correlation between the experimentally measured protein abundances and Reactome pathway terms for the top 174 interacting proteins with the highest significance. Three "modules" could be detected (Figure 3). Module 1 (Figure 3, upper right) is related to "Unblocking and activating NMDA receptors," "Trafficking of AMPA receptors" and "Chemical signaling through the synapse" Reactome terms (including Grial, Gria3, Grin2B, and Dlg4). Module 2 (Figure 3, center), is largely composed of cadherin-, claudin- and catenin-related proteins involved in "Cellular adhesion and junction" functions. Module 3 (Figure 3, bottom left) includes proteins associated in "Axon Guidance" and "Developmental Biology" function.

Taken together, the functional enrichment analysis from these three distinct sources (GO, Reactome and KEGG) indicate that the p140Cap interactors exhibit functions relevant to synaptic structure, synaptic transmission and plasticity.

\section{The p140CAP Interactome within the Structure of the PSD}

Given the enrichment in PSD (Figure 2A), we examined previously described PSD protein network models to assess whether the p140Cap-interacting proteins form structural composites within the PSD or are rather randomly distributed 


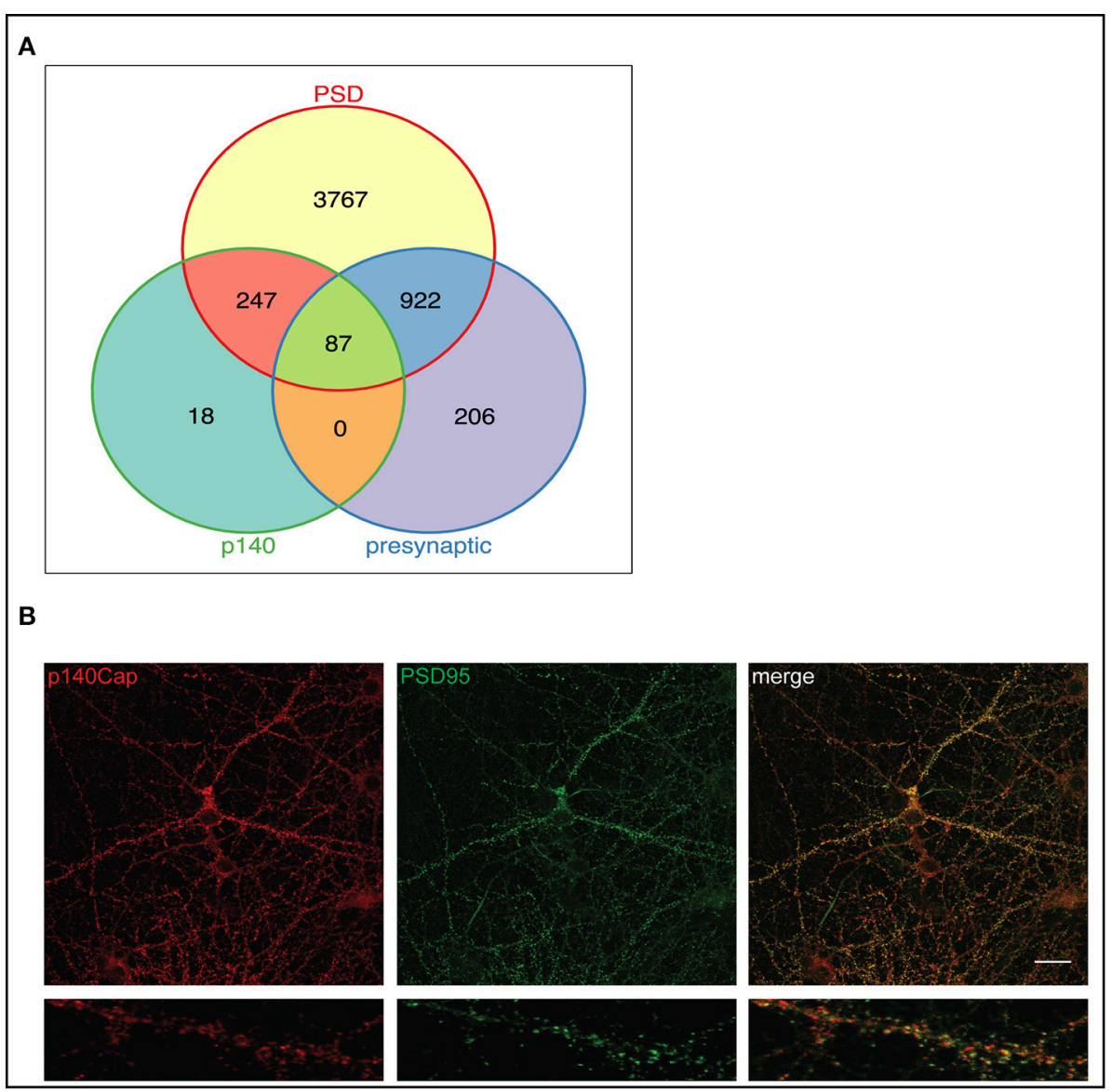

FIGURE 2 | p140Cap interacting proteins distribution in pre- and postsynaptic compartments and functional modules of the p140Cap interactome. (A) Venn diagram showing the overlap of 352 p140Cap interactors (green) mapped in pre- (purple) and postsynaptic (yellow) datasets. (B) p140Cap co-localization with PSD95 on primary hippocampal neurons. DIV 17 hippocampal neurons were stained with antibodies to p140Cap (red) and to PSD95 (green). Merge is shown on the right (Upper panels) Scale bar $20 \mu \mathrm{m}$. Magnification of a segment of dendrite is shown in lower panels.

throughout the network. We built a protein-protein interaction (PPI) network based on a human PSD protein dataset combined with the interaction data from several public databases (see Materials and Methods and Mclean Colin et al., 2016 for details). Spectral cluster analysis was performed on the network as described in Mclean Colin et al. (2016). Within the PSD network of 1,312 proteins, we identified 60 structural clusters based on the network topography. Essentially each cluster contains proteins that are more densely connected to other proteins within the cluster than to proteins elsewhere in the network (Figure 4).

Functional enrichment was tested for each of the clusters to assess structure/function relationships within the molecular network (the distribution of the proteins between the clusters and enrichment results are shown in Supplementary Table S4). We then mapped the p140Cap-interacting proteins onto the network and identified the clusters that are more strongly enriched for p140Cap-interacting proteins compared to a random distribution. We found 4 clusters with significant over-representation for p140Cap-interacting proteins: Cluster 7 (Figure 4B) (14/61, $P=3.5 \mathrm{E}-02)$, Cluster $17(12 / 21$,
$P=3.62002 \mathrm{E}-06)$, Cluster $22(28 / 80, P=7.05 \mathrm{E}-07)$, and Cluster $23(13 / 39, P=1.4 \mathrm{E}-03)$. Cluster 22 (Figure 4D) is overrepresented with GO BP "glutamate receptor signaling pathway," "endocytosis," "cell-cell signaling," and "synaptic transmission" terms and contains the main PSD scaffolding proteins of the MAGUK family and their interactors. This cluster was also significantly enriched with proteins from functional Module 1 (see Figure 3). Cluster 23 (Figure 4E), was found to be associated with GO BP term "cell junction assembly," and was enriched with proteins from Module 2 (see Figure 3). Cluster 7 (Figure 4B), was overrepresented with the "cytoskeleton organization," "actin cytoskeleton organization" and "cell junction assembly" terms and it contains proteins from Module 3 (Figure 3, Supplementary Table S4).

\section{Co-expression Analysis of p140CAP Interactors}

To assess whether the expression of p140Cap interacting proteins could also be co-regulated, we isolated the top significant 174 p140Cap-interacting proteins with an unequivocal Entrez 


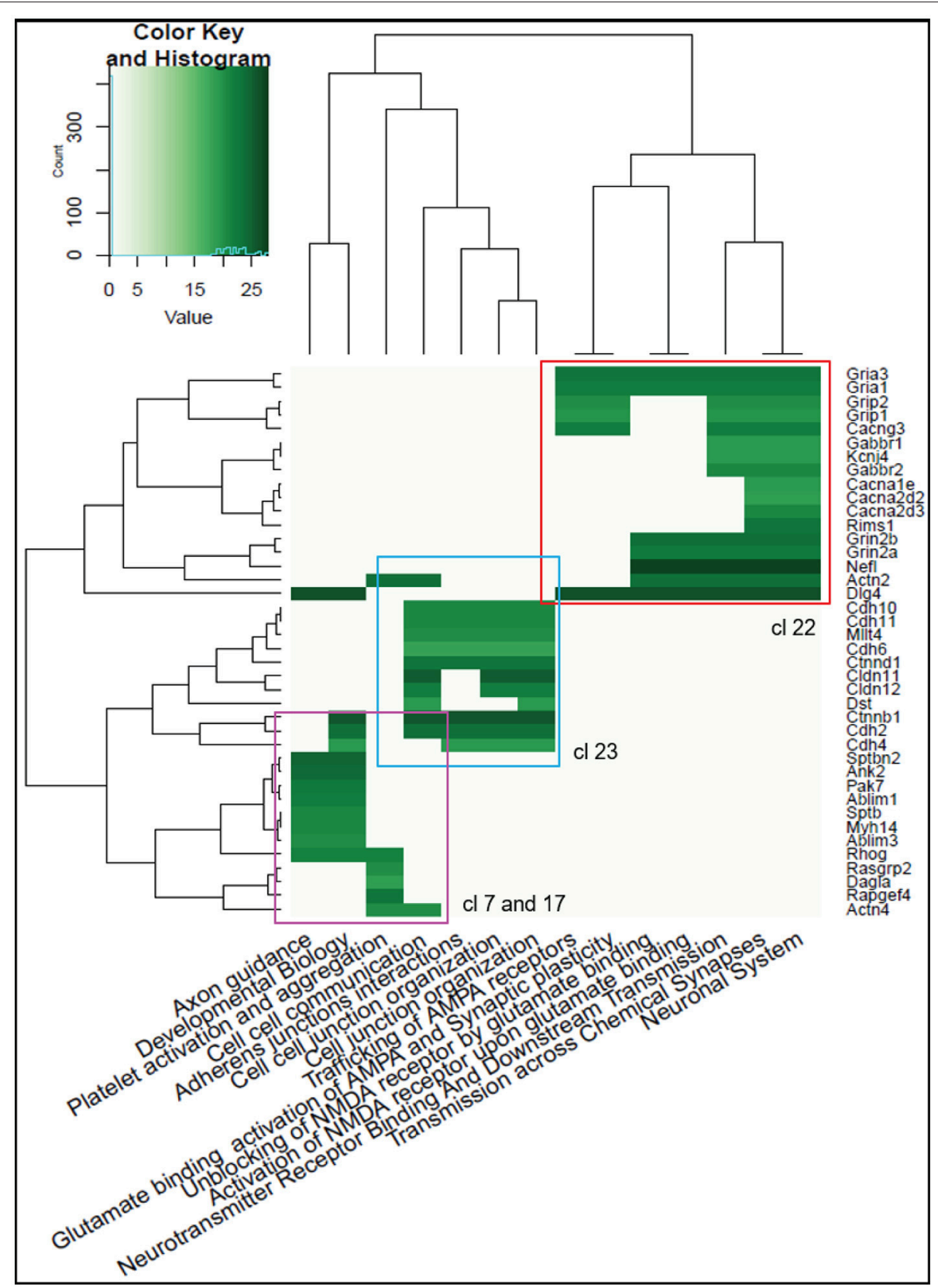

FIGURE 3 | Heatmap of the Reactome Pathway enrichment analysis clustering. Intensity is based on the average relative protein abundance in MS. Three main modules are observed: upper right, Module 1; center, Module 2; and, bottom left, Module 3.

gene ID and tested their co-expression using 18 humanmouse conserved co-expression networks (CCNs) (Piro et al., 2011).

We found a statistically significant number of p140Cap interactors co-expressed with p140Cap in "All Samples," "Normal Tissues," "Brain," and "Central Nervous System" conserved coexpression networks (Supplementary Tables S5, S6). The coexpression across p140Cap interactors was also significant in six CCNs (Supplementary Table S7), including "All Samples," "Normal Tissues," "Brain," and "Central Nervous System" networks (Supplementary Table S8).
Overall, these data show that the network of p140Capinteracting proteins also reflects a gene co-expression cluster (Figure 5), indicating that the components of the p140Cap interactome might undergo coordinated mechanisms of tissuespecific transcription control.

\section{Disease Enrichment of p140Cap Related Proteins}

Synaptic dysfunction has emerged as a common theme in neurological and psychiatric disorders, and recent large-scale genetic studies in ASD and schizophrenia (De Rubeis et al., 2014; 


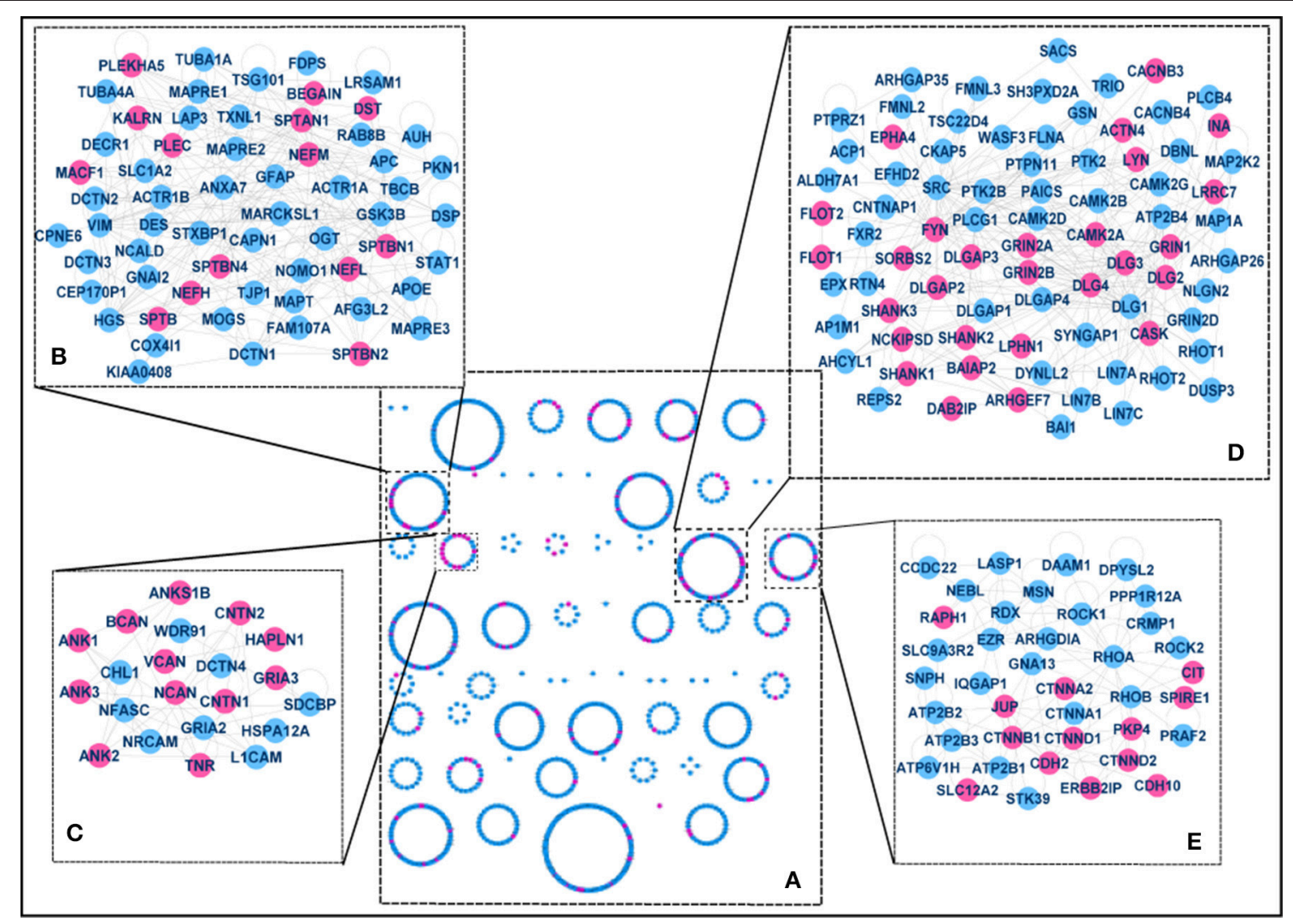

FIGURE 4 | The p140Cap-interactome within the PSD (A) Clusters in the full PSD network. 60 structural clusters where obtained, including 4 significantly enriched for p140Cap-interacting proteins (purple), magnified in panels B-E. (B) Components of Cluster 7. The cluster is overrepresented with "cytoskeleton organization," "actin cytoskeleton organization," and "cell junction assembly" terms and contains p140Cap interactors from Module 3. (C) Components of Cluster 17. This cluster is associated with trans-synaptic signaling and contains p140Cap interacting proteins from Module 3. (D) Components of Cluster 22. The cluster includes the main MAGUK and scaffold proteins and associated with "glutamate receptor signaling pathway," "endocytosis," "cell-cell signaling," and "synaptic transmission" terms and contains the majority of the proteins from Module 1. (E) Components of Cluster 23. The cluster is associated with cell adhesion function and cell junction functions and is enriched with proteins from Module 2.

Fromer et al., 2014) have further strengthened this hypothesis. The pathophysiological mechanisms might include abnormal expression of discrete synaptic proteins or the inability to organize into functional macromolecular complexes (Bayes et al., 2011). We investigated the disease enrichment of the genes encoding p140Cap interacting molecules (351 genes), using genedisease annotation data collected from OMIM (http://omim. org/) and Ensembl variation (Chen et al., 2010) databases mapped onto the HDO tree using the topOnto package (https:// github.com/statbio/topOnto). These analyses yielded a core background list of 14,111 gene-disease associations mapped onto 1,491 HDO terms. We also considered lists of risk genes and loci emerged from recent studies, including ASD (Sanders et al., 2015), epilepsy (EuroEPINOMIC-RES Consortium, 2014), Bipolar Disorder (Kataoka et al., 2016) and Schizophrenia (Fromer et al., 2014; Schizophrenia Working Group of the Psychiatric Genomics, 2014). The 826 gene-disease associations resulting from these analyses were then merged with the annotation set from the databases, yielding a total of 14,357 genedisease associations mapped onto 1,491 HDO terms. Using the Topology-based Elimination Fisher method (Alexa et al., 2006), we found that the p140Cap dataset is significantly enriched for genes associated with schizophrenia $(P=2.1 \mathrm{E}-9)$, ASD $(P=$ 7.9E-6), bipolar disorder ( $P=5.3 \mathrm{E}-5)$, ID (1.1E-3), and epilepsy (1.7E-3) (Table 1, Supplementary Table S9).

Moreover, a further and independent evidence in supporting the role of p140Cap in neurological diseases came from the observation that the largest connected component of the subnetwork of co-expression links of p140Cap-interactors among themselves and p140Cap in the All Tissues CCN contains several genes labeled as Disease Genes and involved in neurological diseases. These results indicate that p140Cap pathways, defined by both protein-protein interactions and gene co-expression data, are relevant to psychiatric and neurological disorders.

\section{DISCUSSION}

The structure and the combinatorial use of a handful of modulatory elements give rise to complexity at subcellular, cellular, and systems level at the synapse (Grant et al., 2016). The loss or modification of key synaptic proteins can directly 


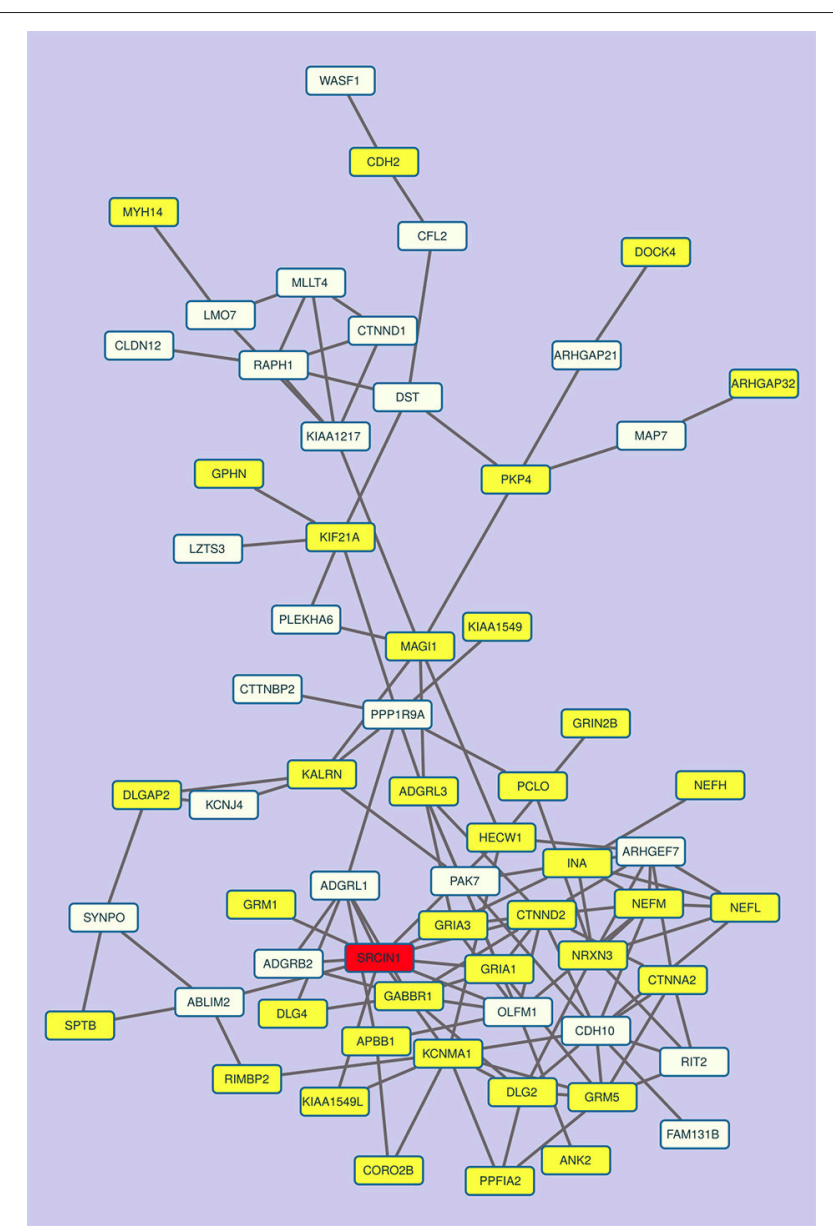

FIGURE 5 | The co-expression sub-network of p140Cap and its interactors contains relevant disease genes. The most connected component of the co-expression network in "All Tissues CCN." p140Cap is shown in red, disease genes are in yellow.

affect such network, ultimately impacting synaptic function. Our results allow to propose that the p140Cap adaptor molecule acts as a key hub of synaptic networks. Our work is the first comprehensive proteomic analysis of the synaptic interactome of p140Cap, which is indispensable for dendritic spine initiation and maturation and forms of hippocampal synaptic plasticity (Repetto et al., 2014). Our data show that the most prominent localization of p140Cap is within the PSD, with a significant enrichment for pathways related to receptors trafficking and chemical signaling through the synapse, cellular adhesion and junction, and axon guidance. We also provide evidence that the p140Cap interactome forms a gene co-expression module. Although p140Cap itself has not been implicated in brain disease yet, our results unveil a robust association of the p140Cap interactome with neurological and psychiatric disorders, including schizophrenia, ID, epilepsy and ASD.

Some of the p140Cap-interacting proteins associated to brain disorders have unknown functions in the brain. By mapping them to the synaptic p140Cap interactome, our study provides functional cues on these disease genes, including ROGDI, FRMD4A, and TRANK1. Loss of ROGDI, encoding a protein with unknown function, causes Kohlschutter-Tonz syndrome (MIM 614574), which presents with psychomotor delay, early-onset intractable seizures, variable ID correlating with the severity of seizures, and amelogenesis imperfect (Schossig et al., 2012). Genetic disruption of FRMD4A causes a syndrome characterized by congenital microcephaly accompanied by agenesis of corpus callosum and/or partial hypoplasia of the vermis and cerebellum and ID (Fine et al., 2015) (MIM 616819). FRMD4A regulates cell polarity in non-neuronal cells (Ikenouchi and Umeda, 2010) and the microcephaly and brain malformations reported in carriers of FRMD4A mutations are compatible with defects in cell polarity in neuronal progenitors and/or newborn neurons. Beyond early brain development, our data also point to a synaptic function for FRMD4A. TRANK1 is a GWAS-associated locus for both schizophrenia (Schizophrenia Working Group of the Psychiatric Genomics, 2014) and bipolar disorder (Chen et al., 2013; Muhleisen et al., 2014), but its functional roles in neurons are obscure. Again, our results locate it in the p140Cap synaptic network.

There is robust evidence supporting the hypothesis that synaptic dysfunction is a shared mechanism underlying a broad range of brain disorders, and our data further corroborate it. For example, alterations in glutamatergic transmission can result in a broad spectrum of psychiatric conditions. In our dataset, we detected AMPA and NMDA receptor subunits associated with schizophrenia (i.e., GRIA1 and GRIN2A) and with a spectrum of DD/ID, ASD and seizures, often in co-morbidity (GRIA3, GRIN1, GRIN2A, and GRIN2B). Glutamatergic transmission is intertwined with synaptic calcium dynamics (Higley and Sabatini, 2012), and large-scale genetic studies have shown that disruption of voltage-gated calcium channels is a pathological mechanism across psychiatric disorders (Cross-Disorder Group of the Psychiatric Genomics, 2013). Notably, this pathway holds potential for rapid therapeutic intervention (Lencz and Malhotra, 2015). Seven VGCC subunits were found in the p140Cap interactome and four of them are associated to disease. CACNA1A haploinsufficiency can cause episodic ataxia type 2 (MIM 108500), familial hemiplegic migraine type 1 (MIM 141500) and spinocerebellar ataxia 6 (MIM 183086). More recently, CACNA1A mutations have been described in individuals diagnosed with ID, epilepsy, ADHD and/or ASD (Damaj et al., 2015). CACNA2D1 and CACNA2D2 are both associated with epilepsy and ID (Edvardson et al., 2013; Pippucci et al., 2013; Vergult et al., 2015), while CACN2D3 has been recently implicated in ASD (De Rubeis et al., 2014). Interestingly, none of the reproducible GWAS-associated loci in schizophrenia CACNA1C, CACNA1H, and CACNB2 (Schizophrenia Working Group of the Psychiatric Genomics, 2014) was detected in our dataset. However, several RIM proteins that are necessary for VGCCs regulation, including the schizophrenia-associated RIMS1 (Schizophrenia Working Group of the Psychiatric Genomics, 2014), are detected in the p140Cap interactome.

Psychiatric manifestations are often accompanied by defects in neuronal morphogenesis, and abnormalities of dendritic spines (either the number or the shape), which are one of 
TABLE 1 | Disease enrichment of p140Cap related proteins.

\begin{tabular}{|c|c|c|c|c|c|c|}
\hline TERM.ID & Term & Annotated & Significant & Expected & classicFisher & elimFisher \\
\hline DOID:5419 & Schizophrenia & 1600 & 65 & 30.54 & 2.1E-09 & 2.1E-09 \\
\hline DOID:12849 & ASD & 338 & 20 & 6.45 & 7.9E-06 & 7.9E-06 \\
\hline DOID:3312 & Bipolar disorder & 981 & 37 & 18.72 & 5.3E-05 & 5.3E-05 \\
\hline DOID:1059 & Intellectual disability & 490 & 20 & 9.35 & 1.18E-03 & 1.18E-03 \\
\hline DOID:1826 & Epilepsy & 331 & 15 & 6.32 & $1.78 \mathrm{E}-03$ & $1.78 \mathrm{E}-03$ \\
\hline
\end{tabular}

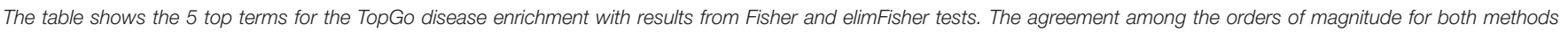
indicates the strong over-representation of respective disease genes among the p140Cap interacting proteins.

the most robust neuroanatomical correlate of ID and often a finding in ASD and schizophrenia (Penzes et al., 2011). p140Cap and many of its interactors play a role in the formation, maturation and maintenance of dendritic spines. Specifically, deficiency of p140Cap results in an excess of immature filopodiallike protrusions at the expenses of mature mushroom spines (Tomasoni et al., 2013; Repetto et al., 2014). Depletion, ablation or mutations of many p140Cap interactors, including CNKSR2 (CNK2) (Lim et al., 2014), CTNNB1 ( $\beta$-catenin) (Okuda et al., 2007), CTNND2 ( $\delta$-catenin) (Arikkath et al., 2009), phenocopy these defects. Conversely, other p140Cap-associated proteins are needed for spine maintenance and their silencing results in reduced spine density and/or spine shrinkage, as documented for CASK (Chao et al., 2008) and ANK3 (Smith et al., 2014). All these genes are associated with psychiatric conditions, ranging from ID i.e., CNKSR2 (Kessels and Malinow, 2009; Vaags et al., 2014), CTNNB1 (Tucci et al., 2014), ANK3 (Iqbal et al., 2013), CASK (Tarpey et al., 2009) and ASD i.e., CTNND2 (Turner et al., 2015), ANK3 (Iqbal et al., 2013) to schizophrenia i.e., CNKSR2 (GWAS, PGC-SCZ 2014) and bipolar disorder ANK3 (Ferreira et al., 2008).

Similarly, the impairment in LTP and LTD and the deficits in memory and learning observed in the p140Cap KO mice (Repetto et al., 2014) could be sustained by improper functioning and/or localisation of several of these newly identified p140Cap interactors, such as the NMDARs subunits, the AMPA receptors, PSD-95, and the Shank family. GRIN1, GRIN2A, and GRIN2B are key in LTP induction, synaptic plasticity, learning and memory (Bliss and Collingridge, 1993; Bliss et al., 2014; Shipton and Paulsen, 2014). Synaptic trafficking of AMPARs is necessary for the induction of LTP, and GluR1-deficient mice exhibit impaired hippocampus-dependent spatial working memory and one-trial spatial memory (Kessels and Malinow, 2009). In mice lacking PSD-95, NMDA-dependent LTP and LTD frequency is shifted to enhanced LTP, consistent with severely impaired spatial learning (Migaud et al., 1998). Mice mutant for Shank proteins exhibit a large spectrum of defects in LTP and LTD (Yoo et al., 2014). Identifying the molecular complexes controlling forms of plasticity that underlie memory consolidation and retrieval has direct implications for ID and associated co-morbidities, including ASD and ADHD. It is also important for psychiatric disorders with a cognitive impairment component and/or with a premorbid cognitive deficit, as documented in schizophrenia (Reichenberg et al., 2010).
As mentioned above, SRCIN1 has not been genetically associated with psychiatric disorders. A de novo missense variant resulting in a p.Glu912Asp change predicted to be probably damaging by the bioinformatic predictor Polyphen-2 and not detected in the 60,706 unrelated controls of the Exome Aggregation Database (ExAC) was found in a schizophrenia cohort (Fromer et al., 2014). Further, based on the data in ExAC, SRCIN1 is significantly depleted in both loss-of-function and missense variants, indicating that the gene is highly intolerant to detrimental variation and so likely a source of disease risk if mutated.

In conclusion, our findings place p140Cap at the crossroad of a highly susceptible synaptic network disrupted in psychiatric and neurological disorders. These findings reinforce the current hypothesis that synaptic dysfunction is a component of all these disorders and have repercussions on our understanding of the underpinnings of psychiatric disorders and their shared comorbidity.

\section{ETHICS STATEMENT}

This study was carried out in accordance with the recommendations of Italian Ministry of Health. The protocol was approved by the Their Commitee with the number 49/2014-PR.

\section{AUTHOR CONTRIBUTIONS}

AAl, CA, IR, and AM, design, collection and assembly of data, data analysis and interpretation; AAd, YC, and EB collection and analysis of MS data; OS, JA, CM, UA, SD, JB, and AB data analysis and interpretation; AAl, OS, JA, SD, EM. MM, ET, and PD design, interpretation of the data and manuscript writing. All the authors contributed to draft the work or revise it critically for important intellectual content. All the authors gave a final approval of the version to be published. All the authors agree be accountable for all aspects of the work in ensuring that questions related to the accuracy or integrity of any part of the work are appropriately investigated and resolved.

\section{FUNDING}

This work was supported by MIUR (Ministero Università Ricerca, PRIN 2010/2011, 2015 to PD), AIRC (Associazione 
Italiana Ricerca Cancro) to PD (IG-15399); Compagnia San Paolo, Torino; Progetto d'Ateneo, Università di Torino 2011 to PD and ET. AAd and YC thank the ProFi Infrastructure (ANR-10-INBS-08-01) for support. EM and MM received funding from Cariplo 2012 grant agreement 0560, Fondazione Vodafone 2017-2018; Regione Lombardia-CNR 2017-2019, Italian Ministry of Health 2015-2017. OS, CM, and JA received funding from the European Union's Horizon 2020 research and innovation program under grant agreement No. 720270.

\section{REFERENCES}

Alexa, A., Rahnenfuhrer, J., and Lengauer, T. (2006). Improved scoring of functional groups from gene expression data by decorrelating GO graph structure. Bioinformatics 22, 1600-1607. doi: 10.1093/bioinformatics/ btl140

Arikkath, J., Peng, I. F., Ng, Y. G., Israely, I., Liu, X., Ullian, E. M., et al. (2009). Delta-catenin regulates spine and synapse morphogenesis and function in hippocampal neurons during development. J. Neurosci. 29, 5435-5442. doi: 10.1523/JNEUROSCI.0835-09.2009

Aronson, A. R., and Lang, F. M. (2010). An overview of MetaMap: historical perspective and recent advances. J. Am. Med. Inform. Assoc. 17, 229-236. doi: 10.1136/jamia.2009.002733

Bayes, A., Collins, M. O., Galtrey, C. M., Simonnet, C., Roy, M., Croning, M. D., et al. (2014). Human post-mortem synapse proteome integrity screening for proteomic studies of postsynaptic complexes. Mol. Brain 7:88. doi: 10.1186/s13041-014-0088-4

Bayes, A., van de Lagemaat, L. N., Collins, M. O., Croning, M. D., Whittle, I. R., Choudhary, J. S., et al. (2011). Characterization of the proteome, diseases and evolution of the human postsynaptic density. Nat. Neurosci. 14, 19-21. doi: 10.1038/nn.2719

Berto, G., Camera, P., Fusco, C., Imarisio, S., Ambrogio, C., Chiarle, R., et al. (2007). The Down syndrome critical region protein TTC3 inhibits neuronal differentiation via RhoA and Citron kinase. J. Cell Sci. 120(Pt 11), 1859-1867. doi: $10.1242 /$ jcs.000703

Betancur, C., and Buxbaum, J. D. (2013). SHANK3 haploinsufficiency: a "common" but underdiagnosed highly penetrant monogenic cause of autism spectrum disorders. Mol. Autism 4:17. doi: 10.1186/2040-2392-4-17

Bliss, T. V., and Collingridge, G. L. (1993). A synaptic model of memory: longterm potentiation in the hippocampus. Nature 361, 31-39. doi: 10.1038/36 $1031 \mathrm{a} 0$

Bliss, T. V., Collingridge, G. L., and Morris, R. G. (2014). Synaptic plasticity in health and disease: introduction and overview. Philos. Trans. R. Soc. Lond. B Biol. Sci. 369:20130129. doi: 10.1098/rstb.2013.0129

Boyken, J., Gronborg, M., Riedel, D., Urlaub, H., Jahn, R., and Chua, J. J. (2013). Molecular profiling of synaptic vesicle docking sites reveals novel proteins but few differences between glutamatergic and GABAergic synapses. Neuron 78, 285-297. doi: 10.1016/j.neuron.2013.02.027

Brinkmalm, A., Brinkmalm, G., Honer, W. G., Moreno, J. A., Jakobsson, J., Mallucci, G. R., et al. (2014). Targeting synaptic pathology with a novel affinity mass spectrometry approach. Mol. Cell. Proteomics 13, 2584-2592. doi: 10.1074/mcp.M114.040113

Chao, H. W., Hong, C. J., Huang, T. N., Lin, Y. L., and Hsueh, Y. P. (2008). SUMOylation of the MAGUK protein CASK regulates dendritic spinogenesis. J. Cell Biol. 182, 141-155. doi: 10.1083/jcb.200712094

Chassefeyre, R., Martinez-Hernandez, J., Bertaso, F., Bouquier, N., Blot, B., Laporte, M., et al. (2018). Regulation of postsynaptic function by the dementia-related ESCRT-III subunit CHMP2B. J. Neurosci. 35, 3155-3173. doi: 10.1523/JNEUROSCI.0586-14.2015

Chatr-Aryamontri, A., Breitkreutz, B. J., Oughtred, R., Boucher, L., Heinicke, S., Chen, D., et al. (2015). The BioGRID interaction database: 2015 update. Nucleic Acids Res. 43:D470-8. doi: 10.1093/nar/gku1204

\section{ACKNOWLEDGMENTS}

$\mathrm{SD}$ is a Seaver fellow. This project has been approved by the Internal Bioethical Committee of the Department.

\section{SUPPLEMENTARY MATERIAL}

The Supplementary Material for this article can be found online at: http://journal.frontiersin.org/article/10.3389/fnmol. 2017.00212/full\#supplementary-material

Chen, D. T., Jiang, X., Akula, N., Shugart, Y. Y., Wendland, J. R., Steele, C. J., et al. (2013). Genome-wide association study meta-analysis of European and Asianancestry samples identifies three novel loci associated with bipolar disorder. Mol. Psychiatry 18, 195-205. doi: 10.1038/mp.2011.157

Chen, Y., Cunningham, F., Rios, D., McLaren, W. M., Smith, J., Pritchard, B., et al. (2010). Ensembl variation resources. BMC Genomics 11:293. doi: 10.1186/1471-2164-11-293

Chin, L. S., Nugent, R. D., Raynor, M. C., Vavalle, J. P., and Li, L. (2000). SNIP, a novel SNAP-25-interacting protein implicated in regulated exocytosis. J. Biol. Chem. 275, 1191-200. doi: 10.1074/jbc.275.2.1191

Cox, J., and Mann, M. (2008). MaxQuant enables high peptide identification rates, individualized p.p.b.-range mass accuracies and proteome-wide protein quantification. Nat. Biotechnol. 26, 1367-1372. doi: 10.1038/nbt.1511

Cross-Disorder Group of the Psychiatric Genomics, C. (2013). Identification of risk loci with shared effects on five major psychiatric disorders: a genome-wide analysis. Lancet 381, 1371-1379. doi: 10.1016/S0140-6736(12)62129-1

Damaj, L., Lupien-Meilleur, A., Lortie, A., Riou, E., Ospina, L. H., Gagnon, L., et al. (2015). CACNA1A haploinsufficiency causes cognitive impairment, autism and epileptic encephalopathy with mild cerebellar symptoms. Eur. J. Hum. Genet. 23, 1505-1512. doi: 10.1038/ejhg.2015.21

Damez-Werno, D. M., Sun, H., Scobie, K. N., Shao, N., Rabkin, J., Dias, C., et al. (2016). Histone arginine methylation in cocaine action in the nucleus accumbens. Proc. Natl. Acad. Sci. U.S.A. 113, 9623-9628. doi: $10.1073 /$ pnas. 1605045113

Deciphering Developmental Disorders, S. (2015). Large-scale discovery of novel genetic causes of developmental disorders. Nature 519, 223-228. doi: 10.1038/nature14135

De Rubeis, S., He, X., Goldberg, A. P., Poultney, C. S., Samocha, K., Cicek, A. E., et al. (2014). Synaptic, transcriptional and chromatin genes disrupted in autism. Nature 515, 209-215. doi: 10.1038/nature13772

Di Stefano, P., Cabodi, S., Boeri Erba, E., Margaria, V., Bergatto, E., Giuffrida, M. G., et al. (2004). P130Cas-associated protein (p140Cap) as a new tyrosinephosphorylated protein involved in cell spreading. Mol. Biol. Cell 15, 787-800. doi: 10.1091/mbc.E03-09-0689

Di Stefano, P., Damiano, L., Cabodi, S., Aramu, S., Tordella, L., Praduroux, A., et al. (2007). p140Cap protein suppresses tumour cell properties, regulating Csk and Src kinase activity. EMBO J. 26, 2843-2855. doi: 10.1038/sj.emboj.7601724

Dosemeci, A., Makusky, A. J., Jankowska-Stephens, E., Yang, X., Slotta, D. J., and Markey, S. P. (2007). Composition of the synaptic PSD-95 complex. Mol. Cell. Proteomics 6, 1749-1760. doi: 10.1074/mcp.M700040-MCP200

Edvardson, S., Oz, S., Abulhijaa, F. A., Taher, F. B., Shaag, A., Zenvirt, S., et al. (2013). Early infantile epileptic encephalopathy associated with a high voltage gated calcium channelopathy. J. Med. Genet. 50, 118-123. doi: 10.1136/jmedgenet-2012-101223

Endele, S., Rosenberger, G., Geider, K., Popp, B., Tamer, C., Stefanova, I., et al. (2010). Mutations in GRIN2A and GRIN2B encoding regulatory subunits of NMDA receptors cause variable neurodevelopmental phenotypes. Nat. Genet. 42, 1021-1026. doi: 10.1038/ng.677

Farr, C. D., Gafken, P. R., Norbeck, A. D., Doneanu, C. E., Stapels, M. D., Barofsky, D. F., et al. (2004). Proteomic analysis of native metabotropic glutamate receptor 5 protein complexes reveals novel molecular constituents. J. Neurochem. 91, 438-450. doi: 10.1111/j.1471-4159.2004.02735.x 
Ferreira, M. A., O’Donovan, M. C., Meng, Y. A., Jones, I. R., Ruderfer, D. M., Jones, L., et al. (2008). Collaborative genome-wide association analysis supports a role for ANK3 and CACNA1C in bipolar disorder. Nat. Genet. 40, 1056-1058. doi: 10.1038/ng.209

Fine, D., Flusser, H., Markus, B., Shorer, Z., Gradstein, L., Khateeb, S., et al. (2015). A syndrome of congenital microcephaly, intellectual disability and dysmorphism with a homozygous mutation in FRMD4A. Eur. J. Hum. Genet. 23, 1729-1734. doi: 10.1038/ejhg.2014.241

Fossati, G., Morini, R., Corradini, I., Antonucci, F., Trepte, P., Edry, E., et al. (2015). Reduced SNAP-25 increases PSD-95 mobility and impairs spine morphogenesis. Cell Death Differ. 22, 1425-1436. doi: 10.1038/cdd.2014.227

Frei, J. A., and Stoeckli, E. T. (2016). SynCAMs-From axon guidance to neurodevelopmental disorders. Mol. Cell. Neurosci. 81, 41-48. doi: 10.1016/j.mcn.2016.08.012

Fromer, M., Pocklington, A. J., Kavanagh, D. H., Williams, H. J., Dwyer, S., Gormley, P., et al. (2014). De novo mutations in schizophrenia implicate synaptic networks. Nature 506, 179-184. doi: 10.1038/nature12929

Gallone, G., Simpson, T. I., Armstrong, J. D., and Jarman, A. P. (2011). Bio::Homology::InterologWalk-a Perl module to build putative proteinprotein interaction networks through interolog mapping. BMC Bioinform. 12:289. doi: 10.1186/1471-2105-12-289

Gorini, G., Ponomareva, O., Shores, K. S., Person, M. D., Harris, R. A., and Mayfield, R. D. (2010). Dynamin-1 co-associates with native mouse brain BKCa channels: proteomics analysis of synaptic protein complexes. FEBS Lett. 584, 845-851. doi: 10.1016/j.febslet.2009.12.061

Grant, S. G. (2012). Synaptopathies: diseases of the synaptome. Curr. Opin. Neurobiol. 22, 522-529. doi: 10.1016/j.conb.2012.02.002

Grant, S. G., Bagni, C., and O'Dell, T. J. (2016). Synaptopathy-from biology to therapy. Neuropharmacology 100:1. doi: 10.1016/j.neuropharm.2015.08.022

Gronborg, M., Pavlos, N. J., Brunk, I., Chua, J. J., Munster-Wandowski, A., Riedel, D., et al. (2010). Quantitative comparison of glutamatergic and GABAergic synaptic vesicles unveils selectivity for few proteins including MAL2, a novel synaptic vesicle protein. J. Neurosci. 30, 2-12. doi: 10.1523/JNEUROSCI.4074-09.2010

Hamdan, F. F., Gauthier, J., Spiegelman, D., Noreau, A., Yang, Y., Pellerin, S., et al. (2009). Mutations in SYNGAP1 in autosomal nonsyndromic mental retardation. N. Engl. J. Med. 360, 599-605. doi: 10.1056/NEJMoa0805392

Higley, M. J., and Sabatini, B. L. (2012). Calcium signaling in dendritic spines. Cold Spring Harb. Perspect. Biol. 4:a005686. doi: 10.1101/cshperspect.a005686

Ikenouchi, J., and Umeda, M. (2010). FRMD4A regulates epithelial polarity by connecting Arf6 activation with the PAR complex. Proc. Natl. Acad. Sci. U.S.A. 107, 748-753. doi: 10.1073/pnas.0908423107

Iqbal, Z., Vandeweyer, G., van der Voet, M., Waryah, A. M., Zahoor, M. Y., Besseling, J. A., et al. (2013). Homozygous and heterozygous disruptions of ANK3: at the crossroads of neurodevelopmental and psychiatric disorders. Hum. Mol. Genet. 22, 1960-1970. doi: 10.1093/hmg/ddt043

Ito, H., Atsuzawa, K., Sudo, K., Di Stefano, P., Iwamoto, I., Morishita, R., et al. (2008). Characterization of a multidomain adaptor protein, p140Cap, as part of a pre-synaptic complex. J. Neurochem. 107, 61-72. doi: 10.1111/j.1471-4159.2008.05585.x

Jaworski, J., Kapitein, L. C., Gouveia, S. M., Dortland, B. R., Wulf, P. S., Grigoriev, I., et al. (2009). Dynamic microtubules regulate dendritic spine morphology and synaptic plasticity. Neuron 61, 85-100. doi: 10.1016/j.neuron.2008.11.013

Kataoka, M., Matoba, N., Sawada, T., Kazuno, A. A., Ishiwata, M., Fujii, K., et al. (2016). Exome sequencing for bipolar disorder points to roles of de novo loss-of-function and protein-altering mutations. Mol. Psychiatry 21, 885-893. doi: $10.1038 / \mathrm{mp} .2016 .69$

Kerrien, S., Aranda, B., Breuza, L., Bridge, A., Broackes-Carter, F., Chen, C., et al. (2012). The IntAct molecular interaction database in 2012. Nucleic Acids Res. 40, D841-6. doi: 10.1093/nar/gkr1088

Kessels, H. W., and Malinow, R. (2009). Synaptic AMPA receptor plasticity and behavior. Neuron 61, 340-350. doi: 10.1016/j.neuron.2009.01.015

Kim, H. G., Kishikawa, S., Higgins, A. W., Seong, I. S., Donovan, D. J., Shen, Y., et al. (2008). Disruption of neurexin 1 associated with autism spectrum disorder. Am. J. Hum. Genet. 82, 199-207. doi: 10.1016/j.ajhg.2007. 09.011
Lencz, T., and Malhotra, A. K. (2015). Targeting the schizophrenia genome: a fast track strategy from GWAS to clinic. Mol. Psychiatry 20, 820-826. doi: $10.1038 / \mathrm{mp} .2015 .28$

Lim, J., Ritt, D. A., Zhou, M., and Morrison, D. K. (2014). The CNK2 scaffold interacts with vilse and modulates Rac cycling during spine morphogenesis in hippocampal neurons. Curr. Biol. 24, 786-792. doi: 10.1016/j.cub.2014.02.036

Luscher, C., and Malenka, R. C. (2012). NMDA receptor-dependent long-term potentiation and long-term depression (LTP/LTD). Cold Spring Harb. Perspect. Biol. 4:a005710. doi: 10.1101/cshperspect.a005710

Manabe, T., Togashi, H., Uchida, N., Suzuki, S. C., Hayakawa, Y., Yamamoto, M., et al. (2000). Loss of cadherin-11 adhesion receptor enhances plastic changes in hippocampal synapses and modifies behavioral responses. Mol. Cell. Neurosci. 15, 534-546. doi: 10.1006/mcne.2000.0849

Martinez-Quiles, N., Ho, H. Y., Kirschner, M. W., Ramesh, N., and Geha, R. S. (2004). Erk/Src phosphorylation of cortactin acts as a switch on-switch off mechanism that controls its ability to activate N-WASP. Mol. Cell. Biol. 24, 5269-5280. doi: 10.1128/MCB.24.12.5269-5280.2004

Mclean, C., He, X., Simpson, I. T., and Armstrong, J. D. (2016). Improved functional enrichment analysis of biological networks using scalable modularity based clustering. J. Proteomics Bioinform. 9, 009-018. doi: 10.4172/jpb.1000383

Migaud, M., Charlesworth, P., Dempster, M., Webster, L. C., Watabe, A. M., Makhinson, M., et al. (1998). Enhanced long-term potentiation and impaired learning in mice with mutant postsynaptic density-95 protein. Nature 396, 433-439. doi: 10.1038/24790

Morciano, M., Beckhaus, T., Karas, M., Zimmermann, H., and Volknandt, W. (2009). The proteome of the presynaptic active zone: from docked synaptic vesicles to adhesion molecules and maxi-channels. J. Neurochem. 108, 662-675. doi: 10.1111/j.1471-4159.2008.05824.x

Morciano, M., Burre, J., Corvey, C., Karas, M., Zimmermann, H., and Volknandt, W. (2005). Immunoisolation of two synaptic vesicle pools from synaptosomes: a proteomics analysis. J. Neurochem. 95, 1732-1745. doi: 10.1111/j.1471-4159.2005.03506.x

Muhleisen, T. W., Leber, M., Schulze, T. G., Strohmaier, J., Degenhardt, F., Treutlein, J., et al. (2014). Genome-wide association study reveals two new risk loci for bipolar disorder. Nat. Commun. 5:3339. doi: 10.1038/ncomms4339

Musen, M. A., Noy, N. F., Shah, N. H., Whetzel, P. L., Chute, C. G., Story, M. A., et al. (2012). The national center for biomedical ontology. J. Am. Med. Inform. Assoc. 19, 190-195. doi: 10.1136/amiajnl-2011-000523

Newman, M. E. (2006). Finding community structure in networks using the eigenvectors of matrices. Phys. Rev. E Stat. Nonlin. Soft Matter Phys. 74(3 Pt 2):036104. doi: 10.1103/PhysRevE.74.036104

Okuda, T., Yu, L. M., Cingolani, L. A., Kemler, R., and Goda, Y. (2007). betaCatenin regulates excitatory postsynaptic strength at hippocampal synapses. Proc. Natl. Acad. Sci. U.S.A. 104, 13479-13484. doi: 10.1073/pnas.0702334104

Penzes, P., Cahill, M. E., Jones, K. A., VanLeeuwen, J. E., and Woolfrey, K. M. (2011). Dendritic spine pathology in neuropsychiatric disorders. Nat. Neurosci. 14, 285-293. doi: 10.1038/nn.2741

Pippucci, T., Parmeggiani, A., Palombo, F., Maresca, A., Angius, A., Crisponi, L., et al. (2013). A novel null homozygous mutation confirms CACNA2D2 as a gene mutated in epileptic encephalopathy. PLoS ONE 8:e82154. doi: 10.1371/journal.pone.0082154

Piro, R. M., Ala, U., Molineris, I., Grassi, E., Bracco, C., Perego, G. P., et al. (2011). An atlas of tissue-specific conserved coexpression for functional annotation and disease gene prediction. Eur. J. Hum. Genet. 19, 1173-1180. doi: 10.1038/ejhg.2011.96

Rauch, A., Wieczorek, D., Graf, E., Wieland, T., Endele, S., Schwarzmayr, T., et al. (2012). Range of genetic mutations associated with severe non-syndromic sporadic intellectual disability: an exome sequencing study. Lancet 380, 1674-1682. doi: 10.1016/S0140-6736(12)61480-9

Reichenberg, A., Caspi, A., Harrington, H., Houts, R., Keefe, R. S., Murray, R. M., et al. (2010). Static and dynamic cognitive deficits in childhood preceding adult schizophrenia: a 30-year study. Am. J. Psychiatry 167, 160-169. doi: 10.1176/appi.ajp.2009.09040574

Repetto, D., Aramu, S., Boeri Erba, E., Sharma, N., Grasso, S., Russo, I., et al. (2013). Mapping of p140Cap phosphorylation sites: the EPLYA and EGLYA motifs have a key role in tyrosine phosphorylation and Csk binding, and are substrates of the Abl kinase. PLoS ONE 8:e54931. doi: 10.1371/journal.pone.0054931 
Repetto, D., Camera, P., Melani, R., Morello, N., Russo, I., Calcagno, E., et al. (2014). p140Cap regulates memory and synaptic plasticity through Src-mediated and citron-N-mediated actin reorganization. J. Neurosci. 34, 1542-1553. doi: 10.1523/JNEUROSCI.2341-13.2014

Robison, A. J. (2014). Emerging role of CaMKII in neuropsychiatric disease. Trends Neurosci. 37, 653-662. doi: 10.1016/j.tins.2014.07.001

Sanders, S. J., He, X., Willsey, A. J., Ercan-Sencicek, A. G., Samocha, K. E., Cicek, A. E., et al. (2015). Insights into autism spectrum disorder genomic architecture and biology from 71 Risk Loci. Neuron 87, 1215-1233. doi: 10.1016/j.neuron.2015.09.016

Schaefer, M. H., Fontaine, J. F., Vinayagam, A., Porras, P., Wanker, E. E., and Andrade-Navarro, M. A. (2012). HIPPIE: integrating protein interaction networks with experiment based quality scores. PLoS ONE 7:e31826. doi: 10.1371/journal.pone.0031826

Schizophrenia Working Group of the Psychiatric Genomics, C. (2014). Biological insights from 108 schizophrenia-associated genetic loci. Nature 511, 421-427. doi: $10.1038 /$ nature 13595

Schossig, A., Wolf, N. I., Fischer, C., Fischer, M., Stocker, G., Pabinger, S., et al. (2012). Mutations in ROGDI cause kohlschutter-tonz syndrome. Am. J. Hum. Genet. 90, 701-707. doi: 10.1016/j.ajhg.2012.02.012

Schriml, L. M., Arze, C., Nadendla, S., Chang, Y. W., Mazaitis, M., Felix, V., et al. (2012). Disease Ontology: a backbone for disease semantic integration. Nucleic Acids Res. 40, D940-6. doi: 10.1093/nar/gkr972

Schwanhausser, B., Busse, D., Li, N., Dittmar, G., Schuchhardt, J., Wolf, J., et al. (2011). Global quantification of mammalian gene expression control. Nature 473, 337-342. doi: 10.1038/nature10098

Shipton, O. A., and Paulsen, O. (2014). GluN2A and GluN2B subunit-containing NMDA receptors in hippocampal plasticity. Philos. Trans. R. Soc. Lond. B Biol. Sci. 369, 20130163. doi: 10.1098/rstb.2013.0163

Simpson, T. I., Armstrong, J. D., and Jarman, A. P. (2010). Merged consensus clustering to assess and improve class discovery with microarray data. BMC Bioinform. 11:590. doi: 10.1186/1471-2105-11-590

Smith, K. R., Kopeikina, K. J., Fawcett-Patel, J. M., Leaderbrand, K., Gao, R., Schurmann, B., et al. (2014). Psychiatric risk factor ANK3/ankyrin-G nanodomains regulate the structure and function of glutamatergic synapses. Neuron 84, 399-415. doi: 10.1016/j.neuron.2014.10.010

Sweatt, J. D. (2016). Neural plasticity and behavior-sixty years of conceptual advances. J. Neurochem. 139(Suppl. 2), 179-199. doi: 10.1111/jnc.13580

Tarpey, P. S., Smith, R., Pleasance, E., Whibley, A., Edkins, S., Hardy, C., et al. (2009). A systematic, large-scale resequencing screen of X-chromosome coding exons in mental retardation. Nat. Genet. 41, 535-543. doi: 10.1038/ ng.367

Tomasoni, R., Repetto, D., Morini, R., Elia, C., Gardoni, F., Di Luca, M., et al. (2013). SNAP-25 regulates spine formation through postsynaptic binding to p140Cap. Nat. Commun. 4:2136. doi: 10.1038/ncomms 3136

Tucci, V., Kleefstra, T., Hardy, A., Heise, I., Maggi, S., Willemsen, M. H., et al. (2014). Dominant beta-catenin mutations cause intellectual disability with recognizable syndromic features. J. Clin. Invest. 124, 1468-1482. doi: $10.1172 /$ JCI70372
Turner, T. N., Sharma, K., Oh, E. C., Liu, Y. P., Collins, R. L., Sosa, M. X., et al. (2015). Loss of delta-catenin function in severe autism. Nature 520, 51-56. doi: $10.1038 /$ nature 14186

Uruno, T., Liu, J., Zhang, P., Fan, Y., Egile, C., Li, R., et al. (2001). Activation of Arp2/3 complex-mediated actin polymerization by cortactin. Nat. Cell Biol. 3, 259-266. doi: 10.1038/35060051

Vaags, A. K., Bowdin, S., Smith, M. L., Gilbert-Dussardier, B., Brocke-Holmefjord, K. S., Sinopoli, K., et al. (2014). Absent CNKSR2 causes seizures and intellectual, attention, and language deficits. Ann. Neurol. 76, 758-764. doi: 10.1002/ana.24274

Vergult, S., Dheedene, A., Meurs, A., Faes, F., Isidor, B., Janssens, S., et al (2015). Genomic aberrations of the CACNA2D1 gene in three patients with epilepsy and intellectual disability. Eur. J. Hum. Genet. 23, 628-632. doi: 10.1038/ejhg.2014.141

Vizcaino, J. A., Csordas, A., del-Toro, N., Dianes, J. A., Griss, J., Lavidas, I., et al. (2016). 2016 update of the PRIDE database and its related tools. Nucleic Acids Res. 44, D447-D456. doi: 10.1093/nar/gkv1145

Weingarten, J., Lassek, M., Mueller, B. F., Rohmer, M., Lunger, I., Baeumlisberger D., et al. (2014). The proteome of the presynaptic active zone from mouse brain. Mol. Cell. Neurosci. 59, 106-118. doi: 10.1016/j.mcn.2014.02.003

Whetzel, P. L., Noy, N. F., Shah, N. H., Alexander, P. R., Nyulas, C., Tudorache, T., et al. (2011). BioPortal: enhanced functionality via new web services from the national center for biomedical ontology to access and use ontologies in software applications. Nucleic Acids Res. 39, W541-W545. doi: 10.1093/nar/gkr469

Wilhelm, B. G., Mandad, S., Truckenbrodt, S., Krohnert, K., Schafer, C., Rammner, B., et al. (2014). Composition of isolated synaptic boutons reveals the amounts of vesicle trafficking proteins. Science 344, 1023-1028. doi: 10.1126/science.1252884

Yang, Y., Wei, M., Xiong, Y., Du, X., Zhu, S., Yang, L., et al. (2015). Endophilin A1 regulates dendritic spine morphogenesis and stability through interaction with p140Cap. Cell Res. 25, 496-516. doi: 10.1038/cr.2015.31

Yoo, J., Bakes, J., Bradley, C., Collingridge, G. L., and Kaang, B. K. (2014). Shank mutant mice as an animal model of autism. Philos. Trans. R. Soc. Lond. B Biol. Sci. 369:20130143. doi: 10.1098/rstb.2013.0143

Yu, G., Wang, L. G., Han, Y., and He, Q. Y. (2012). clusterProfiler: an R package for comparing biological themes among gene clusters. Omics 16, 284-287. doi: 10.1089/omi.2011.0118

Conflict of Interest Statement: The authors declare that the research was conducted in the absence of any commercial or financial relationships that could be construed as a potential conflict of interest.

Copyright (C) 2017 Alfieri, Sorokina, Adrait, Angelini, Russo, Morellato, Matteoli, Menna, Boeri Erba, McLean, Armstrong, Ala, Buxbaum, Brusco, Couté, De Rubeis, Turco and Defilippi. This is an open-access article distributed under the terms of the Creative Commons Attribution License (CC BY). The use, distribution or reproduction in other forums is permitted, provided the original author(s) or licensor are credited and that the original publication in this journal is cited, in accordance with accepted academic practice. No use, distribution or reproduction is permitted which does not comply with these terms. 